\title{
SIRTA, a ground-based atmospheric observatory for cloud and aerosol research
}

\author{
M. Haeffelin ${ }^{1}$, L. Barthès ${ }^{2}$, O. Bock ${ }^{3}$, C. Boitel ${ }^{1}$, S. Bony ${ }^{1}$, D. Bouniol ${ }^{2}$, H. Chepfer ${ }^{1}$, M. Chiriaco ${ }^{1}$, J. Cuesta $^{1}$, \\ J. Delanoë ${ }^{2}$, P. Drobinski ${ }^{3}$, J.-L. Dufresne ${ }^{1}$, C. Flamant $^{3}$, M. Grall ${ }^{1}$, A. Hodzic $^{1}$, F. Hourdin ${ }^{1}$, F. Lapouge ${ }^{1}$, \\ Y. Lemaître ${ }^{2}$, A. Mathieu ${ }^{1}$, Y. Morille ${ }^{1}$, C. Naud ${ }^{4}$, V. Noël ${ }^{5}$, W. O'Hirok ${ }^{6}$, J. Pelon ${ }^{3}$, C. Pietras ${ }^{1}$, A. Protat ${ }^{2}$, \\ B. Romand ${ }^{1}$, G. Scialom ${ }^{2}$, and R. Vautard ${ }^{1}$ \\ ${ }^{1}$ Laboratoire de Météorologie Dynamique, Institut Pierre Simon Laplace, Ecole Polytechnique, 91128 Palaiseau Cedex, \\ France \\ ${ }^{2}$ Centre d'Etudes des Environnements Terrestre et Planétaire, Institut Pierre Simon Laplace, 10-12 Avenue de l'Europe, \\ 78140 Velizy, France \\ ${ }^{3}$ Service d'Aéronomie, Institut Pierre Simon Laplace, Universite Pierre et Marie Curie, 4, Place Jussieu, 75252 Paris \\ Cedex 05, France \\ ${ }^{4}$ University College London, Geomatic Engineering, University College London, Gower Str, London WC1E 6BT, UK \\ ${ }^{5}$ Analytical Services and Materials, Hampton, VA 23666, USA \\ ${ }^{6}$ Institute for Computational Earth System Science, University of California, Santa Barbara, California, USA
}

Received: 3 September 2004 - Revised: 28 October 2004 - Accepted: 2 November 2004 - Published: 28 February 2005

\begin{abstract}
Ground-based remote sensing observatories have a crucial role to play in providing data to improve our understanding of atmospheric processes, to test the performance of atmospheric models, and to develop new methods for future space-borne observations. Institut Pierre Simon Laplace, a French research institute in environmental sciences, created the Site Instrumental de Recherche par Télédétection Atmosphérique (SIRTA), an atmospheric observatory with these goals in mind. Today SIRTA, located $20 \mathrm{~km}$ south of Paris, operates a suite a state-of-the-art active and passive remote sensing instruments dedicated to routine monitoring of cloud and aerosol properties, and key atmospheric parameters. Detailed description of the state of the atmospheric column is progressively archived and made accessible to the scientific community. This paper describes the SIRTA infrastructure and database, and provides an overview of the scientific research associated with the observatory. Researchers using SIRTA data conduct research on atmospheric processes involving complex interactions between clouds, aerosols and radiative and dynamic processes in the atmospheric column. Atmospheric modellers working with SIRTA observations develop new methods to test their models and innovative analyses to improve parametric representations of sub-grid processes that must be accounted for in the model. SIRTA provides the means to develop data interpretation tools for future active remote sensing missions in space (e.g. CloudSat
\end{abstract}

Correspondence to: M. Haeffelin

(martial.haeffelin@1md.polytechnique.fr) and CALIPSO). SIRTA observation and research activities take place in networks of atmospheric observatories that allow scientists to access consistent data sets from diverse regions on the globe.

Key words. Atmospheric composition and structure (Cloud physics; Aerosols and particles; Convective processes)

\section{Introduction}

The role of clouds remains a major uncertainty in current-day climate change simulations. Validation of these model simulations requires increasingly comprehensive observations of clouds and their precursors, such as aerosols and water vapour (e.g. Lau and Crane, 1997; Tselioudis and Jakob, 2002; Williams et al., 2003; Bony et al., 2004). Along with expanding satellite programs that provide global coverage of an increasing number of key parameters of the climate system, ground-based observations continue to evolve and develop. The continuous nature of ground-based remote sensing observations makes them particularly suited to monitor fine scale processes that involve complex interactions between clouds, aerosols, and radiative and dynamic processes.

Several programs have been successful in establishing global or regional networks dedicated to monitoring a few atmospheric parameters, generally focusing on a single type of remote sensing instrument (e.g. the Aerosol Research SunPhotometer Network, AERONET, Holben et al., 1998; the 
European aerosol lidar network, EARLINET, Schneider et al., 2000; the Baseline Surface Radiation Network, BSRN, Ohmura et al., 1998). As researchers explore more and more complex processes, such as the life cycle of clouds and their diverse conditions of formation and dissipation, the necessity of operating highly instrumented observatories, sometimes called super-sites, becomes more and more evident. The development and operation of such facilities require a large community of experts in visible, infrared, and microwave remote sensing, using both high or narrow spectral resolution and broad-band information, with both active and passive remote sensing experience. To date, a limited number of programs have been able to establish long-term observatories that take advantage of the capabilities provided by extended instrument synergies (e.g. the U.S. Atmospheric Radiation Measurement Program, ARM, Stokes and Schwartz, 1994; the Utah University based Facility for Atmospheric Remote Sensing, FARS, Sassen et al., 2001; the Dutch Cabauw Experimental Site for Atmospheric Research, CESAR, Ulden and Wierenga, 1996).

Despite important progress and significant contributions from these programs (e.g. Ackerman and Stokes, 2003), major uncertainties remain in the quantification of the impact of clouds and aerosols on the global climate. The usefulness of such observatories for climate studies is best demonstrated when atmospheric modellers are actively involved. Routine and detailed monitoring of clouds and aerosols throughout the atmospheric column provide unique data-sets to evaluate the performance of atmospheric models and to develop parametric representations that more reliably simulate unresolved processes (e.g. Morcrette, 2002; Guichard et al., 2003). Ground-based remote-sensing data point out processes that are not taken into account in current-day models (e.g. Hogan et al., 2002).

Ground-based observatories are also crucial for satellite observations. State-of-the-art remote sensing instruments operating in a coordinated manner on ground sites open the path to develop future space-borne missions. The performance of cutting-edge technology can be tested against well established standards and promising instrument synergies can be evaluated before a satellite mission reaches even phase A. Ground-based monitoring has been providing and continues to provide key validation data to satellite remote sensing missions (e.g. Sassen and Cho, 1992; Naud et al., 2003).

In an effort to provide a concrete solution to the need for better observation data sets, the "Site Instrumental de Recherche par Télédétection Atmosphérique", SIRTA, a French observatory dedicated to the remote sensing of clouds and aerosols was created around the research communities of Institut Pierre Simon Laplace (IPSL). IPSL is a French research institute in environmental sciences that federates six national research laboratories of the Paris metropolitan area, involved in both Earth observation from space and from the ground and in atmospheric modelling.

The site infrastructure and remote sensing instruments are described in Sect. 2. Section 3 provides information on the
SIRTA database. Section 4 presents research activities on atmospheric processes related to clouds in the free troposphere and the boundary layer, which are illustrated through two case studies. Conclusions and prospective activities are given in Sect. 5.

\section{SIRTA infrastructure}

SIRTA is the atmospheric observatory of IPSL for cloud and aerosol research. The IPSL research laboratories dedicated to atmospheric research are:

- Centre d'études des Environnements Terrestres et Planétaires (CETP)

- Laboratoire de Météorologie Dynamique (LMD)

- Laboratoire des Sciences du Climat et de l'Environnement (LSCE)

- Service d'Aéronomie (SA).

At CETP, LMD, LSCE and SA scientists are involved in process study research, atmospheric modelling (climate, weather, chemistry and transport), satellite observation programs, and atmospheric remote sensing from the ground (active and passive techniques). Development of remote sensing instruments has been an active area of research at IPSL laboratories for many years. Instruments such as radars, lidars and radiometers for ground-based and airborne applications were developed to observe atmospheric processes such as boundary layer dynamics, cloud formation and microphysics, precipitation, aerosols and ozone in the urban environment.

\subsection{Remote sensing site}

Latitude and longitude of the SIRTA observatory are $48.713^{\circ} \mathrm{N}$ and $2.208^{\circ} \mathrm{E}$, respectively. SIRTA is located on the campus of Ecole Polytechnique in Palaiseau, a suburban community $20 \mathrm{~km}$ south of Paris. The geographical location of SIRTA in a worldwide context is shown in Fig. 1. The site infrastructure is described in Table 1 . The observatory sits on a $10-\mathrm{km}$ plateau about $160 \mathrm{~m}$ above sea level (see centre panel of Fig. 2). The plateau is a semi-urban environment divided equally in agricultural fields, wooded areas, and housing and industrial developments. The prevailing winds are westerlies, blowing air of maritime origin over the site. North-easterly winds occur quite frequently, as well advecting polluted air from the Paris metropolitan area over the site.

\subsection{Instruments operating routinely at SIRTA}

SIRTA is composed of an ensemble of state-of-the-art active and passive remote sensing instruments, including radars, lidars, and radiometers. The measurement system was developed with sensor synergy in mind. Active remote sensing instruments provide information on the vertical distribution of 


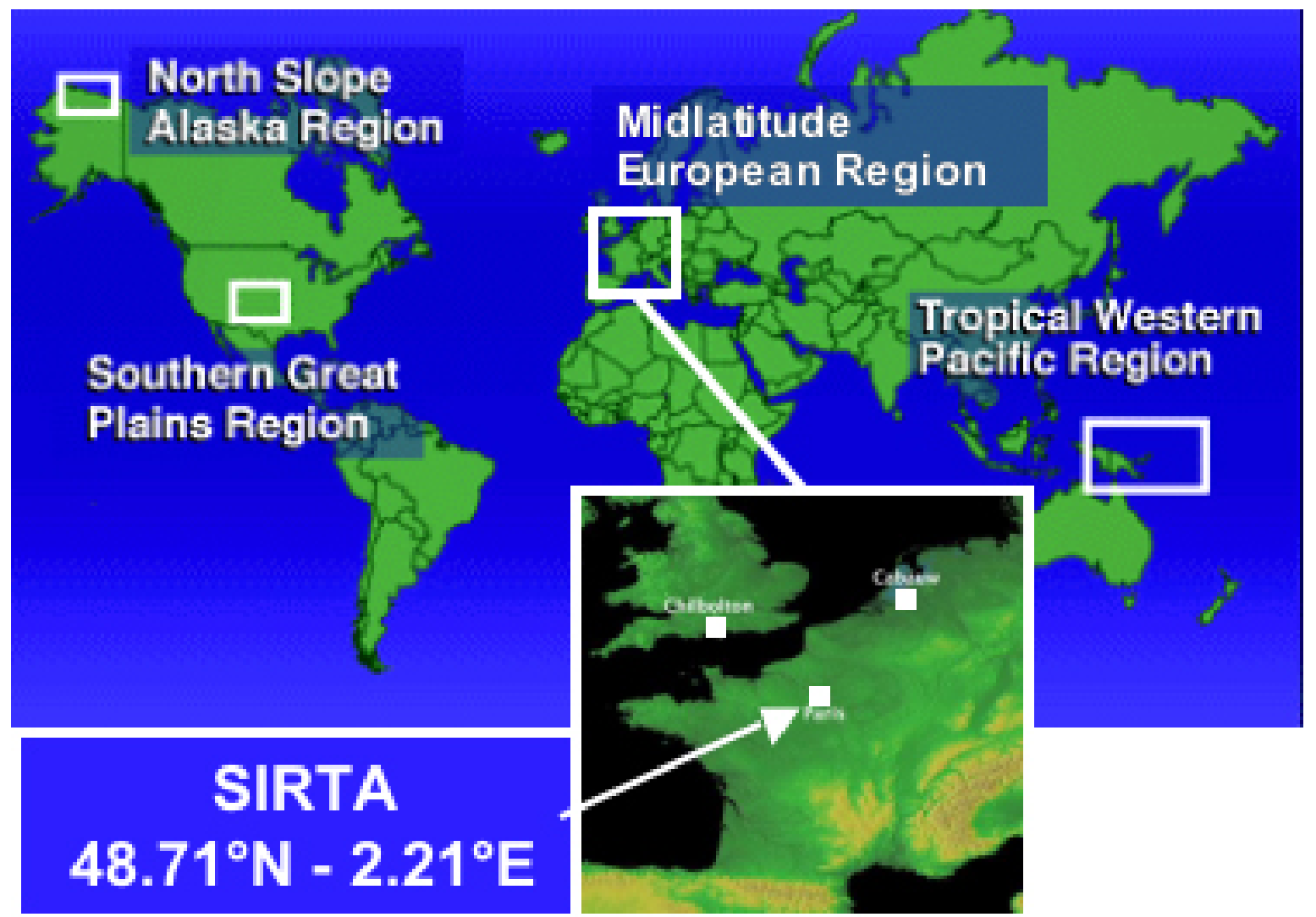

Fig. 1. Location of the SIRTA observatory on a World map in relation to other atmospheric observatories: ARM Program (USA), Chilboton Observatory (UK), and Cabauw experimental site (NL) described in Sect. 3.2.

Table 1. Infrastructure of the SIRTA observatory.

\begin{tabular}{l} 
Site location \\
Platforms \\
Elevated platform \\
Mast \\
\hline Lidar building \\
Network
\end{tabular}

Latitude $48.713^{\circ}$ North
Longitude: $2.208^{\circ}$ East
Altitude $156 \mathrm{~m}$ above mean sea level
Five $200-\mathrm{m} 2$ platforms for transportable instruments
$500-\mathrm{m} 2$ platform with unobstructed field of view $15 \mathrm{~m}$ above ground (roof of 3-
story building). Dedicated acquisition room.
30-m mast for in-situ measurements (weather, turbulent, radiative fluxes)
Dedicated building for Rayleigh/Mie back-scattering lidar
100 Mbit network available at all locations

particles in the atmospheric column (hydrometeors, aerosols) and their properties. Cloud radar and lidar emit waves at millimetre and micrometer wavelength, respectively. Their sensitivities with respect to the size distribution of particles are hence quite complementary. Passive remote sensing instruments measure the cumulative radiance contribution of the whole column. Spectral selection allows contributions from different constituents to be separated. The following subsections provide succinct descriptions of the instruments that constitute the core routine observations at the SIRTA observatory. Instruments are listed in Table 2 and shown in Fig. 2.

\subsubsection{Cloud and aerosol backscattering lidar}

The LNA lidar (LNA stands for Lidar Nuages Aérosols) is an Nd-Yag pulsed lidar developed at LMD for cloud and aerosol remote sensing (Elouragini and Flamant, 1996). The LNA lidar is shown in Fig. 2 (panel a). Laser emission is a $20-\mathrm{Hz}$ pulsed beam at $1064 \mathrm{~nm}$, doubled at $532 \mathrm{~nm}$ and linearly polarized. The laser beam is expanded to augment its diameter and to reduce divergence. Backscattered photons are collected through a narrow field-of-view telescope (NFOV, $0.5 \mathrm{mrad}$ ) and a wide field-of-view telescope (WFOV, $5 \mathrm{mrad}$ ) that range $2-15 \mathrm{~km}$ and $100 \mathrm{~m}-5 \mathrm{~km}$, 


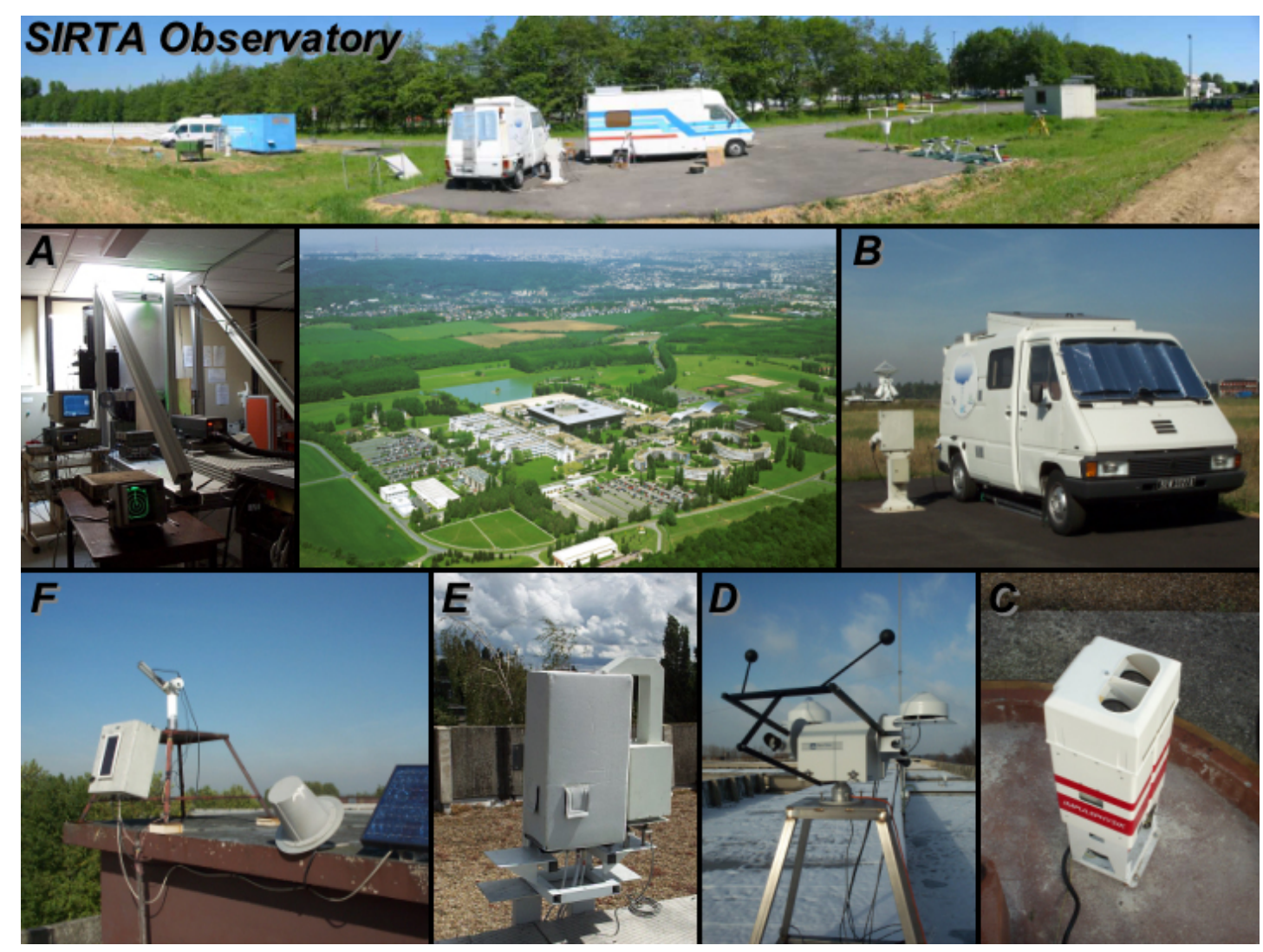

Fig. 2. Photographs the main components of the SIRTA observatory: overall view of the Ecole Polytechnique campus (center panel), measurement platforms (top panel), (A) LNA lidar, (B) RASTA radar, (C) ceilometer, (D) surface radiative flux station, (E) Drakkar MWR, and (F) Sun-photometer.

Table 2. List of instruments operated routinely or continuously at SIRTA.

\begin{tabular}{|c|c|c|c|}
\hline Instrument & $\begin{array}{c}\text { Range } \\
\text { (V: vertical; S: } \\
\text { scan) }\end{array}$ & Area of use & $\begin{array}{l}\text { Instrument PI } \\
\text { (Institute) }\end{array}$ \\
\hline $\begin{array}{l}\text { Backscattering lidar (532, } \\
1064 \mathrm{~nm})\end{array}$ & $0.1-15 \mathrm{~km}\left(\mathrm{~V}^{\star}\right)$ & $\begin{array}{l}\text { Cloud and aerosol } \\
\text { properties }\end{array}$ & C. Pietras (LMD) \\
\hline $95 \mathrm{GHz}$ doppler radar & $0.1-15 \mathrm{~km}(\mathrm{~V})$ & Clouds properties & A. Protat (CETP) \\
\hline $\begin{array}{l}\text { Ceilometer (Impulsphysics } \\
\text { LD40) }\end{array}$ & $0.1-6 \mathrm{~km}(\mathrm{~V})$ & Cloud height & H. Baltink (KNMI) \\
\hline BSRN radiometric station & Surface & Surface radiation budget & M. Haeffelin (IPSL) \\
\hline $\begin{array}{l}\text { Microwave radiometer } \\
(20+30 \mathrm{GHz})\end{array}$ & $\begin{array}{l}\text { Column } \\
\text { integrated }\end{array}$ & Vapor + liquid water & L. Barthès (CETP) \\
\hline $\begin{array}{l}\text { Aeronet/Photons sun- } \\
\text { photometer }\end{array}$ & $\begin{array}{l}\text { Column } \\
\text { integrated }\end{array}$ & Aerosols, water vapor & P. Goloub (LOA) \\
\hline Meteorological station & $\begin{array}{l}\text { Standard } 2 \text { and } \\
10 \mathrm{~m}\end{array}$ & $\begin{array}{l}\text { Surface } \\
\text { thermodynamics }\end{array}$ & C. Pietras (LMD) \\
\hline Radiosondes (Météo-France) & $0-30 \mathrm{~km}(\mathrm{~V})$ & $\begin{array}{l}\text { Vertical wind+PTU } \\
\text { profiles }\end{array}$ & $\begin{array}{l}\text { M. Ruchon (Météo- } \\
\text { France) }\end{array}$ \\
\hline
\end{tabular}

${ }^{*}$ Range depends on time averaging 
respectively, with a vertical resolution of $15 \mathrm{~m}$. Linearly polarized and cross-polarized photons at $532 \mathrm{~nm}$ are detected using two separate optical detection systems.

Vertical distributions of particles are fully characterized from the ground to about $15 \mathrm{~km}$ and the structure of the atmosphere, such as the boundary layer height and the altitudes of aerosol and cloud layers are retrieved. The raw signal from the lidar is not calibrated in an absolute sense, as it depends on the laser emission power. To retrieve particle backscattering or extinction coefficient profiles, the lidar profile must be calibrated. The lidar calibration is performed by normalizing the lidar profile to a computed molecular backscattering profile in a particle-free zone of the troposphere above the boundary layer, typically between 3 and $6 \mathrm{~km}$ altitude. The molecular backscattering profile is derived from temperature and pressure profiles provided by collocated radio-sonde data. The cross-to-linear polarization ratio is used to identify non-spherical particles; in case of cloud layers the ratio is used to separate ice from liquid water. In case of aerosols, the ratio is used to identify larger dust particles. The LNA lidar participated in a lidar inter-calibration campaign carried out in the framework of the European EARLINET project to test system alignments (Matthias et al., 2004).

LNA lidar data are used extensively in cloud and aerosol studies and to validate cloud detection from satellite observations. Chepfer et al. $(1999,2000)$ carried out studies to validate cirrus cloud parameters (cloud top height, occurrence, thermodynamic phase) inferred from the polarized radiometer POLDER-1 measurements. Similarly, Naud et al. (2004) performed a detailed analysis of cloud detection retrievals by multi-angle and high-spectral radiometers on board satellites. In the period 2001-2003, the LNA lidar participated in the European EARLINET project dedicated to monitoring aerosols in the atmospheric column using 21 lidar stations in Europe (e.g. Ansmann et al., 2003).

\subsection{2 $95 \mathrm{GHz}$ Cloud Doppler Radar (RASTA)}

The RASTA (Radar Aéroporté et Sol de Télédétection Atmosphérique) cloud radar operates at SIRTA to document the microphysical and dynamic properties of all types of nonprecipitating clouds. RASTA is a vertically-pointing singlebeam 95-GHz Doppler radar (see Fig. 2, panel b). The system is installed in a van, and hence transportable. The beam width is $0.18^{\circ}$, the sensitivity is about $51 \mathrm{dBZ}$ at $1 \mathrm{~km}$ and the $1.2-\mathrm{m}$ Cassegrain antenna is vertically pointing. The RASTA radar is also designed for airborne applications (using a different antenna and a dual beam configuration) and was involved in several field campaigns. The ground-based configuration of the RASTA cloud radar operates routinely at SIRTA since October 2002.

Absolute calibration of the RASTA radar was performed during an inter-calibration campaign held at the Chilbolton (United Kingdom) and Cabauw (Netherlands) observatories in the February-March 2004 period, in the framework of the CloudNet project, a European pilot network of stations for observing cloud profiles (see CloudNet reference). A first comparison was carried out against the Chilbolton 94 $\mathrm{GHz}$ Galileo radar. Galileo is itself calibrated against 3 and $35 \mathrm{GHZ}$ radars. Galileo calibration constants are checked regularly using radar echoes in light rain (between 3 and $10 \mathrm{~mm} / \mathrm{h}$ ) based on the fact that attenuation by the light rain produces returned power for lower gates that are constant to within $1 \mathrm{dBZ}$ (Hogan et al., 2002). A second comparison was carried out against the $35-\mathrm{GHz}$ Doppler radar of the Cabauw observatory to check the consistency with the absolute calibration obtained from the Chilbolton observatory. As a result, we reached a 1-dBZ consistency between the three CloudNet millimetre-wave radars.

RASTA is devoted to the investigation of cloud processes, through the documentation of the microphysical, radiative, and dynamical cloud properties, using either radar-lidar synergetic algorithms (Tinel et al., 2005) or radar-only methods (Protat et al., 2003). The other objectives are to validate space-borne observations and the representation of clouds in atmospheric models, ranging from the explicit representation of clouds in cloud-resolving models to the cloud parameterizations in weather forecast and climate models.

\subsubsection{Surface radiative flux station}

A Kipp \& Zonen (KZ) AP-2 solar tracker was installed at SIRTA in December 2002 to monitor the downwelling solar and infrared components of the surface radiation budget (Fig. 2, panel d). The tracker carries a $\mathrm{CH} 1$ pyrheliometer, a shaded CM22 pyranometer, and a shaded CG4 pyrgeometer. The pyrheliometer measures the direct or un-scattered solar radiation $(0.3-4.0 \mu \mathrm{m})$, while the shaded pyranometer measures the downwelling diffuse solar radiation scattered by the atmosphere $(0.3-4.0 \mathrm{~mm})$. The two measurements are then combined to produce the total solar radiation incident at the surface, as recommended by the Baseline Surface Radiation Network (Ohmura et al., 1998). The shaded pyrgeometer measures the downwelling infrared radiation incident at the surface $(4.0-40 \mu \mathrm{m})$.

The instruments were factory calibrated by Kipp \& Zonen in 2002. The pyrheliometer is calibrated against an open cavity absolute radiometer (secondary standard) that is itself calibrated every five years against the world radiometric reference, maintained by the World Radiometric Center (WRC) in Davos, using the Sun as source (Direct Radiation). The pyranometer is calibrated against a secondary standard. An inter-comparison between 15 pyranometers (Michalsky et al., 2003) shows that the KZ factory calibration and instrument performance are very satisfactory $\left(1 \mathrm{~W} / \mathrm{m}^{2}\right.$ root mean square error). Comparisons of pyrgeometers performed at the ARM Oklahoma and Alaska sites revealed very good consistency between the KZ CG4 and the WRC absolute skyscanning radiometer (Philipona et al., 2001). Recalibration of solar instruments was performed on site in June 2004 using a PM06 absolute cavity radiometer, using an alternating shading-unshading technique described in Philipona (2002). The CG4 instrument calibration will be calibrated periodically (every other year) by the WRC. 


\subsubsection{Two dual-wavelength micro-wave radiometers}

The Drakkar Microwave Radiometer (D-MWR) is a vertically pointing system developed at CETP that measures radiometric brightness temperature in $\mathrm{K}$ and $\mathrm{Ka}$ bands (see Fig. 2, panel e). The antenna beam-width is $13^{\circ}$ for the 23.8 Ghz channel and $11^{\circ}$ for the 36.8-Ghz channel. Radiometric accuracy is about $1 \mathrm{~K}$. The Rescom Microwave Radiometer (R-MWR) has a two-axis scanning system. The antenna bandwidth is $1.9^{\circ}$. This micro-wave radiometer pair has been used in combination with a spectro-pluviometer to investigate the individual contributions of rain, water vapour, and liquid water at frequencies ranging from $10 \mathrm{GHz}$ to $90 \mathrm{GHz}$ for telecommunication applications.

The D-MWR operates at SIRTA on a continuous mode since January 2001. Thermal protection of the instrument was improved in July 2002 to minimize internal temperature fluctuations. Calibration of the D-MWR is done using the operational radiosondes launched twice daily by MétéoFrance (see Sect. 2.2.6). For each clear-sky episode, synthetic brightness temperatures are computed at the D-MWR frequencies from the radiosonde data using the Kummerow and Weinman (1988) radiative transfer code and compared to the measured brightness temperatures, in order to derive the calibration constants. Absolute calibration is carried out periodically by transferring the R-MWR calibration to the D-MWR. Absolute calibration of the R-MWR is obtained using a tipping-curve technique based on measurements at two or more viewing angles (Han and Westmaster, 2000). In this method, the relationship between atmospheric opacity and viewing angle is used to estimate cosmic brightness temperature. The difference between this estimation and the true value $(2.7 \mathrm{~K})$ is used to derive the calibration of the microwave radiometer.

The D-MWR participated in several field experiments such as the study of ocean-atmosphere coupling and cyclogenesis in the Northern Atlantic, as part of the Fronts and Atlantic Storm-Track Experiment (FASTEX). The D-MWR was used in part to validate satellite retrievals from the Special Sensor Microwave/Imager (SSM/I, Eymard, 2000).

\subsubsection{Multi-wavelength Sun-photometer}

A CIMEL 318-CE Sun-photometer was installed at SIRTA in July 2002, as part of the PHOTONS/AERONET network (Holben et al., 1998). The PHOTONS program is in charge of 25 AERONET sites. The Sun-photometer consists of an optical device mounted on a robot to track the solar disc. A control box receives the collected data and is linked to a transmitter coupled to an antenna that transmits the data through a Meteosat transmission channel. The whole system is powered by batteries coupled to solar panels, allowing for automatic continuous operation (see Fig. 2, panel f). The Sun-photometer data are transmitted hourly to NASA GSFC for analysis and become available on the AERONET web site soon thereafter. A cloud mask is applied to the data to remove cloud contamination (Smirnov et al., 2000). Aerosol optical depth is then provided at four wavelengths (440, 670, 870 , and $1020 \mathrm{~nm})$. In the case of mostly clear conditions, the Sun-photometer measures sky radiances from which aerosol size distributions can be retrieved. Furthermore, polarization measurements are carried out at $870 \mathrm{~nm}$ to complete the aerosol characterizations. Measurements at $940 \mathrm{~nm}$ are also realized to retrieve the integrated water vapor content of the atmosphere. SIRTA technicians perform daily operational checks, such as instrument status and transmission of collected data, and check the cleanliness of the optics on a weekly basis. Long-term maintenance and calibration are performed by the PHOTONS program to ensure consistency with the AERONET database.

\subsubsection{Weather station and radiosonde profiles}

In-situ measurements at SIRTA currently consist of pressure, temperature, humidity, wind direction and speed, and precipitation. Those measurements are performed on the roof platform, on 2-m and 10-m masts. Precipitation data (rate and cumulative) are obtained by a tipping-bucket pluviometer. A second set of sensors was purchased in mid-2004, including temperature, humidity and pressure sensors, installed at $2 \mathrm{~m}$ above ground, as well as a wind vane and anemometer installed at $10 \mathrm{~m}$ above ground. The $10-\mathrm{m}$ level is equipped with a sonic anemometer for high-frequency measurements of heat and moisture fluxes. Radiosonde launches are performed by the French national weather service (Météo-France) twice daily at 00:00 and 12:00 UT from the Trappes regional weather centre, $15 \mathrm{~km}$ west of SIRTA, as part of the Météo-France operational upper-air sounding network.

\subsection{Instruments operating in the framework of field cam- paigns}

SIRTA hosts additional active and passive remote sensing instruments that operate during intensive observation periods. They are usually personnel intensive and cannot be operated continuously. These instruments are listed in Table 3. The doppler lidar and radar presented below are established at SIRTA since 1999.

\subsubsection{Transportable wind lidar}

The LVT (Lidar Vent Transportable or Transportable Wind Lidar, TWL) is a Doppler coherent lidar at $10.6 \mu \mathrm{m}$, with a typical range resolution of $300 \mathrm{~m}$ in line-of-sight (LOS). The maximum range is greater than $10 \mathrm{~km}$ shot-to-shot in horizontal LOS. The LVT lidar can detect cirrus clouds (8 to $11 \mathrm{~km}$ ) in vertical LOS. The LVT lidar measures a range resolved line-of-sight wind component. Different scans can be programmed: plan-position indicator (PPI) (scan at fixed elevation angle), range-height indicator (RHI, scan at fixed azimuth angle), conical scans or series of regularly spaced elevation and azimuth angles (raster scan). Wind components can be retrieved from raster-scan data. The limitations for operating conditions are rain, fog and low cloud layers. 
Table 3. List of instruments developed at IPSL and collaborating institute that operate at SIRTA in the context of specific field campaigns.

\begin{tabular}{|c|c|c|c|}
\hline Instrument & $\begin{array}{c}\text { Range } \\
\text { (V: vertical; S: } \\
\text { scan) }\end{array}$ & Area of use & $\begin{array}{l}\text { Instrument PI } \\
\text { (Institute) }\end{array}$ \\
\hline $\begin{array}{l}\text { Doppler Infrared Lidar (10.6 } \\
\mu \mathrm{m})\end{array}$ & $0.3-10 \mathrm{~km}\left(\mathrm{~S}^{\star}\right)$ & Dynamics & P. Drobinski (SA/LMD) \\
\hline $5 \mathrm{GHz}$ Doppler Radar & $0.5-100 \mathrm{~km}(\mathrm{~S})$ & Precipitation & G. Scialom (CETP) \\
\hline DIAL Lidar (266/289/316nm) & $0.1-7 \mathrm{~km}\left(\mathrm{~V}^{*}\right)$ & Ozone, aerosols & G. Ancellet (SA) \\
\hline Raman Lidar (355 nm) & $0.1-7 \mathrm{~km}\left(\mathrm{~S}^{*}\right)$ & Water vapor & O. Bock (SA/IGN) \\
\hline $\begin{array}{l}\text { Infrared radiometer }(8,11,12 \\
\mu \mathrm{m})\end{array}$ & Column integrated & $\begin{array}{l}\text { Brightness } \\
\text { temperature }\end{array}$ & G. Brogniez (LOA/CIMEL) \\
\hline Spectro-pluviometer & Surface & Precipitation & J-Y. Delahaye (CETP) \\
\hline
\end{tabular}

${ }^{*}$ Range depends on time averaging

The LVT was used to investigate the convective atmospheric boundary layer during the ECLAP campaign (Etude de la Couche Limite en Agglomération Parisienne, Drobinski et al., 1998), and the atmospheric boundary layer in complex terrain like mountainous regions during the Mesoscale Alpine Program (MAP) (Drobinski et al., 2003), or urban area and coastal area (Bastin et al., 2005) during the ESCOMPTE campaign (Expérience sur site pour contraindre les modèles de pollution atmosphérique et de transport d'émissions).

\subsubsection{5-GHz dual polarization Doppler radar (RONSARD)}

RONSARD is a C-band ground-based pulsed radar aiming mainly at documenting the dynamic properties of precipitating systems in the troposphere (reflectivity, wind and variance of the wind). This instrument has a 4-m diameter antenna on a trailer. This antenna bears both transmitter and receiver in order to avoid energy losses. The antenna can be programmed to scan consecutive cones at various elevations and various elevation steps. The scan duration is about $30 \mathrm{~s}$ for a complete 360 scan in azimuth at fixed elevation which results in about $9 \mathrm{~min}$ for a complete volume scan (20 elevations). It can also perform RHI scans at fixed azimuth. The maximal range is 100 or $200 \mathrm{~km}$, depending on pulse repetition frequency, with corresponding unfolded velocity $+/-20$ or $+/-10 \mathrm{~m} / \mathrm{s}$, and range resolutions 200 or $400 \mathrm{~m}$, respectively.

Originally, there were two radars until 1990. Since then, only one radar was maintained and improved in order to fulfill another scientific objective, namely the detailed description of the boundary layer in clear air or under cloudy conditions, even in the absence of precipitation. In order to answer this second objective while preserving the first one, the real-time signal processing was modified in 1998. Two campaigns for observing the boundary layer under summer conditions were conducted in 1993 and 1998 (Turbulence Radar

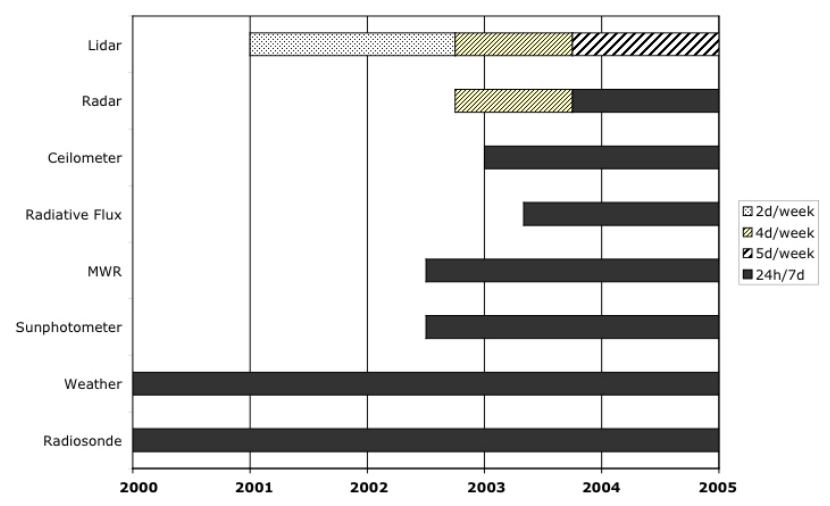

Fig. 3. Types of operations (continuous or routine measurements) for each instrument listed in Table 2.

Aviation Cells, TRAC 93 and 98).

RONSARD (with one or two radars) was the key instrument of several national or international campaigns devoted to deep convection under the tropics (Tropical Deep Convection, COPT 81 in Ivory Coast), to mid-latitudes fronts (FRONTS spring 1984 and FRONTS fall 1987; Lemaître et al., 2001) and mid-latitude convection over complex orography (MAP; Tabary and Scialom, 2001).

A third scientific objective concerns the interactions between microphysics and dynamics, and the role of the ice phase in the organization of precipitation. In order to fulfill this third objective, the Dual polarization (horizontal and vertical) capability is presently being added to RONSARD by means of a second receiver and antenna modification. The additional polarimetric quantities measured are the differential reflectivity, the differential phase shift, and the correlation coefficient at zero lag. Processing these parameters by means of specific algorithms allows us to identify hydrometeors. The dual polarization capability will be operational in 2004. 


\section{SIRTA data}

Figure 3 shows the type of operations achieved for each instrument listed in Table 2 since 2001. Routine LNA lidar measurements ( 2 days per week) were initiated in 2001 and increased to 4 days per week in October 2002 when routine RASTA radar operations began. One year later, 24-h round-the-clock radar operation capability was implemented. In summer 2002, the Drakkar microwave radiometer was reconditioned to improve temperature stability for retrieval of water vapour and liquid water content. A sunphotometer was installed, exploiting the visible and near-infrared end of the spectrum to monitor aerosol properties. In 2003 a ceilometer started to provide continuous day-night monitoring of cloud base height. Simultaneously, a radiometric station was installed to measure the surface radiation budget with instruments designed for long-term monitoring. Surface thermodynamic conditions are monitored at the site since 2001. Météo-France radiosonde profile data are archived since 2001.

\subsection{SIRTA data base}

The data system is designed with three objectives in mind: (1) data quality, (2) timely processing, and (3) data access. Table 4 lists the level-1 data products available in the SIRTA archive. Quality control tests are applied to each data stream. Near-real-time (about one hour after acquisition) processing is performed on the LNA lidar and RASTA radar data streams. Resulting quick-look images appear incrementally on the SIRTA webpage as data is being collected (http://sirta.lmd.polytechnique.fr). Level-1 data (data files + images) become accessible to scientific users on a day +1 basis through file transfer protocol access. Access information is provided on the SIRTA webpage.

Table 5 describes level-2 products that are currently developed by the scientific community involved in SIRTA. Algorithms labelled "OPE" are mature algorithms that are or can be applied on an operational basis to large data-sets. Algorithms labelled "RES" are research algorithms, published or unpublished. "RES" algorithms are applied to selected situations (e.g. thin ice clouds for the lidar-IR microphysics algorithm and thick ice clouds for the radar-lidar microphysics algorithm). Comparison of retrievals based on our algorithms to retrievals by others is part of on-going research.

\subsection{SIRTA data in international databases}

Integration of SIRTA data in international reference databases is actively pursued. The objective is to reach and maintain international quality standards. SIRTA contributes surface radiation data to the BSRN database (Ohmura et al., 1998). Sun-photometer measurements are part of AERONET (Holben et al., 1998). Lidar measurements are integrated in the EARLINET data set (Schneider et al., 2000). Radar and lidar data are part of the CloudNet program.
SIRTA participates in the tropospheric profiling working group of the Global Energy and Water Cycle Experiment (GEWEX) Radiation Panel to enhance cooperation between advanced atmospheric profiling sites. The mission of this network is "to collect consistent data sets of known calibration and quality of the vertical structure of clouds, aerosols, and water vapour, to study their radiative impact." Extended climatic regions are covered with sites in the maritime and continental mid-latitudes: Cabauw (Netherland), Chilbolton (United Kingdom), L'Aquila (Italy), Lindenberg (Germany), Palaiseau (France), and Lamont, Oklahoma (United States); in the Arctic: Barrow, Alaska (United States); and in the Tropics: Darwin (Australia) and Naru Island (United States).

\subsection{Educational outreach}

Each year, over one hundred students from undergraduate and graduate physics, climate and environment programs expand their knowledge on atmospheric remote sensing during experimental work sessions at SIRTA. Students learn about the technical aspects of remote sensing instruments and participate in the acquisition of atmospheric measurements. Then they perform data analysis on those measurements and discuss capabilities and limitations of the systems. Data interpretation tutorials are also offered to scientists and graduate students that are interested in using SIRTA data. These tutorials are available for the algorithms described in Table 5.

\section{SIRTA research}

\subsection{SIRTA research objectives}

Clouds are the main focus of SIRTA research. Clouds developing in the free troposphere are studied extensively at the large scale using passive remote sensing satellite data. Exploiting active remote sensing and multi-spectral synergies, SIRTA research focuses on studying vertical distributions of cloud occurrence, cloud particle shape and size, water contents of clouds and cloud internal dynamics. The retrieval methods recently developed in preparation for the upcoming Cloud-Aerosol Lidar and Infrared Pathfinder Satellite Observations (CALIPSO) and Cloud Radar Pathfinder satellite mission (CloudSat) are described in Sect. 4.2. The dynamics and thermodynamics of the boundary and surface layers are key factors of the formation and life cycle of clouds. The experience acquired in studying turbulent and organized transport of water and energy near the surface is used to test the capability of state-of-the-art parametric representations of boundary layer processes in atmospheric models. Section 4.3 presents a method developed to identify sources of uncertainties in such parametrizations.

As all research activities currently pursued at IPSL and collaborating institutions exploiting SIRTA data cannot be presented in this paper, we list the main topics of research in Table 6. All studies have a common denominator in that they require development of new methods to take advantage of instrument synergies ("SYN" column in Table 6). Extensive 
Table 4. Level-1 data accessible in the SIRTA archive. *Sun-photometer data should be retrieved directly from AERONET.

\begin{tabular}{|c|c|c|c|}
\hline Instrument & Level-1 products & Quality-control procedures & Data access \\
\hline $\begin{array}{l}\text { Back- } \\
\text { scattering } \\
\text { Lidar }\end{array}$ & $\begin{array}{l}\text { - Range-corrected, } \\
\text { non-normalized back- } \\
\text { scattered power (PR }{ }^{2} \text {, } \\
\text { proportional to } \mathrm{m}^{-1} \mathrm{sr}^{-} \\
{ }^{1} \text { ) } \\
\text { - Quality flag }\end{array}$ & $\begin{array}{l}\text { - Removal of electronic noise in analog } \\
\text { signal } \\
\text { - Removal of atmospheric background } \\
\text { contribution } \\
\text { - Identification of geometrical limitation at } \\
\text { near range } \\
\text { - Identification of statistical errors related } \\
\text { to signal-to-noise ratio }\end{array}$ & $\begin{array}{l}\text { VISU: NRT } \\
\text { DATA: } D+1\end{array}$ \\
\hline $95 \mathrm{GHz}$ Radar & $\begin{array}{l}\text { - Reflectivity (DBz) } \\
\text { - Velocity (m/s) } \\
\text { - Variance }\end{array}$ & $\begin{array}{l}\text { - Removal of speckle noise } \\
\text { - Limitation to } 15-\mathrm{km} \text { range }\end{array}$ & $\begin{array}{l}\text { VISU: NRT } \\
\text { DATA: } D+1\end{array}$ \\
\hline Ceilometer & $\begin{array}{l}\text { - Range-corrected, } \\
\text { non-normalized back- } \\
\text { scattered power }\left(\mathrm{PR}^{2} \text {, }\right. \\
\text { proportional to } \mathrm{m}^{-1} \mathrm{sr}^{-} \\
{ }^{1} \text { ) } \\
\text { - Quality flag }\end{array}$ & $\begin{array}{l}\text { - Removal of speckle noise } \\
\text { - Limitation to 8-km range }\end{array}$ & $\begin{array}{l}\text { VISU: } D+1 \\
\text { DATA: } D+1\end{array}$ \\
\hline $\begin{array}{l}\text { Radiometric } \\
\text { Station }\end{array}$ & $\begin{array}{l}\text { Surface downwelling } \\
\text { irradiances }\left(\mathrm{W} \mathrm{m}^{-2}\right) \text { : } \\
\text { - Direct solar } \\
\text { - Diffuse solar } \\
\text { - Global solar } \\
\text { - Longwave }\end{array}$ & $\begin{array}{l}\text { Procedures as per BSRN } \\
\text { recommendations: } \\
\text { - Test physically possible limits } \\
\text { - Test extremely rare limits }\end{array}$ & $\begin{array}{l}\text { VISU: } D+1 \\
\text { DATA: } D+1\end{array}$ \\
\hline $\begin{array}{l}\text { Microwave } \\
\text { radiometer }\end{array}$ & $\begin{array}{l}\text { - Brightness } \\
\text { temperature }\end{array}$ & & $\begin{array}{l}\text { VISU: } D+1 \\
\text { DATA: } D+1\end{array}$ \\
\hline $\begin{array}{l}\text { AERONET } \\
\text { Sun- } \\
\text { photometer* }\end{array}$ & - Radiance $\left(\mathrm{W} \mathrm{m}^{-2} \mathrm{sr}^{-1}\right)$ & QC checks performed by AERONET & $\begin{array}{l}\text { VISU: } \mathrm{D}+1 \\
\text { DATA: } \mathrm{D}+1\end{array}$ \\
\hline Weather station & $\begin{array}{l}\text { - Temperature } \\
\text { - Pressure } \\
\text { - Relative humidity } \\
\text { - Wind module and } \\
\text { direction } \\
\text { - Precipitation rate }\end{array}$ & Test physically possible limits & $\begin{array}{l}\text { VISU: } D+1 \\
\text { DATA: } D+1\end{array}$ \\
\hline $\begin{array}{l}\text { Meteo-France } \\
\text { radiosonde } \\
\text { data }\end{array}$ & $\begin{array}{l}\text { Profiles of temperature, } \\
\text { pressure, relative } \\
\text { humidity, and wind }\end{array}$ & QC checks performed by Météo-France & $\begin{array}{l}\text { VISU: } \mathrm{D}+1 \\
\text { DATA: } \mathrm{D}+1\end{array}$ \\
\hline
\end{tabular}

partnerships have been setup between SIRTA and the modelling research community. This involves researchers that are trained at the model-observation interface and able to provide feedback between models and observations (studies marked in the "MOD" column, Table 6). Similarly, researchers from the satellite community are actively involved in the activities of the observatory, so that it can serve as a preparation platform for future satellite missions (see studies marked "SAT" in Table 6).

\subsection{Cirrus cloud study}

Cirrus clouds have low temperatures and are often semitransparent. Because of these characteristics, they contribute significantly to the natural greenhouse effect, and influence the global cloud radiative equilibrium. Despite important progress in the last 15 years, the quantification of cirrus cloud radiative impact is still unknown. One of the main causes of uncertainty comes from our partial knowledge of their microphysical properties that strongly impact the ice cloud 
Table 5. Retrievals of atmospheric properties (level-2 data) from single or multiple instruments require developments of specific algorithms and are part of active areas of research. *Sun-photometer data should be ordered directly from AERONET.

\begin{tabular}{|c|c|c|c|}
\hline $\begin{array}{l}\text { Instrument/ } \\
\text { data stream }\end{array}$ & Level-2 products & Algorithm & $\begin{array}{l}\text { Pro- } \\
\text { cess }\end{array}$ \\
\hline \multirow{3}{*}{$\begin{array}{l}\text { Back-scattering } \\
\text { Lidar }\end{array}$} & $\begin{array}{l}\text { Cloud and aerosol } \\
\text { vertical structure }\end{array}$ & $\begin{array}{l}\text { Multi-test algorithm applied on } 532-\mathrm{nm} \text { channel to } \\
\text { identify cloud layers, aerosol layers, molecular } \\
\text { layers, and boundary layer height (Morille et al., } \\
\text { 2004) }\end{array}$ & OPE \\
\hline & Optical depth & $\begin{array}{l}\text { Multi-retrieval algorithm applied on 532-nm } \\
\text { channel to retrieve optical depth of cloud or } \\
\text { aerosol layers (Cadet et al., 2004) }\end{array}$ & OPE \\
\hline & $\begin{array}{l}\text { Depolarization and } \\
\text { color ratio }\end{array}$ & $\begin{array}{l}\text { Multi-wavelength algorithms using linear and } \\
\text { cross-polarized } 532-n m \text { and linear } 1064-\mathrm{nm} \\
\text { channels to discriminate particle shape (Noel et } \\
\text { al., 2002) }\end{array}$ & OPE \\
\hline $95 \mathrm{GHz}$ Radar & $\begin{array}{l}\text { Cloud structure } \\
\text { Ice/water content } \\
\text { Particle size distribution }\end{array}$ & $\begin{array}{l}\text { Mean particle diameter from radar reflectivity and } \\
\text { doppler velocity } \\
\text { Size distribution related to mean diameter } \\
\text { Extinction and ice water content function of } \\
\text { reflectivity and size distribution } \\
\text { Retrieval uncertainties estimated } 50 \%\end{array}$ & \\
\hline Ceilometer & Cloud-base height & Vaisala proprietary algorithm & OPE \\
\hline $\begin{array}{l}\text { Radiometric } \\
\text { Station }\end{array}$ & $\begin{array}{l}\text { Fraction of cloud cover } \\
\text { Shortwave and } \\
\text { longwave clear-sky } \\
\text { fluxes }\end{array}$ & $\begin{array}{l}\text { Clear-sky models derived from measurements. } \\
\text { Threshold to identify cloud cover fraction. } \\
\text { (Long and Ackerman 2000) }\end{array}$ & OPE \\
\hline $\begin{array}{l}\text { Microwave } \\
\text { radiometer }\end{array}$ & $\begin{array}{l}\text { Integrated water vapor } \\
\text { and liquid water } \\
\text { content }\end{array}$ & $\begin{array}{l}\text { Brightness temperatures simulated from } \\
\text { radiosonde profiles to calibrate MWR. Water vapor } \\
\text { and liquid water contents inverted using the } \\
\text { Kummerow and Weinman (1988) algorithm. }\end{array}$ & OPE \\
\hline $\begin{array}{l}\text { AERONET } \\
\text { Sun- } \\
\text { photometer* }\end{array}$ & $\begin{array}{l}\text { Optical depth } \\
\text { Angström coefficient } \\
\text { Size distribution }\end{array}$ & See Holben et al. (1998) & OPE \\
\hline \multicolumn{4}{|c|}{ Instrument Synergies } \\
\hline $\begin{array}{l}\text { Lidar }+ \\
\text { narrowband } \\
\text { infrared } \\
\text { radiometer }\end{array}$ & Ice-cloud microphysics & $\begin{array}{l}\text { Improved split-window technique using lidar-IR } \\
\text { synergies to retrieve cirrus cloud particle size and } \\
\text { shape (Chiriaco et al., 2004) }\end{array}$ & RES \\
\hline \multirow{3}{*}{ Radar + Lidar } & Cloud vertical structure & Combination of radar and lidar cloud masks & OPE \\
\hline & $\begin{array}{l}\text { Cloud structure } \\
\text { Ice/water content } \\
\text { Particle size distribution }\end{array}$ & $\begin{array}{l}\text { Normalized particle size distribution } \mathrm{No}^{*} \text { (with } \\
\text { respect to mean diameter) } \\
\text { Lidar extinction: } \alpha=s \mathrm{No}^{*(1-t)} Z^{t} \\
\text { lce water content: IWC=a No*(1-b)} Z^{b} \\
\text { (Tinel et al., 2004) }\end{array}$ & RES \\
\hline & $\begin{array}{l}\text { Particle terminal } \\
\text { velocity } \\
\text { Vertical air velocity }\end{array}$ & $\begin{array}{l}\text { Terminal velocity function of radar reflectivity and } \\
\text { particle shape } \\
\text { Doppler velocity= air + terminal velocity } \\
\text { (Protat et al., 2003) }\end{array}$ & RES \\
\hline
\end{tabular}


Table 6. Description of main research activities exploiting SIRTA data. "SYN" identifies studies that include developing methods in instrument synergy; "MOD" labels those involving model-to-observation comparisons; "SAT" indicates studies that require satellite data or that develop techniques that can be used on satellite data for large-scale applications.

\begin{tabular}{|c|c|c|c|c|}
\hline Topic & Description & SYN & MOD & SAT \\
\hline \multirow[t]{7}{*}{ Clouds } & $\begin{array}{l}\text { Cloud radiative impact and life cycle: } \\
\text { - Development of new remote sensing techniques based on } \\
\text { instrument synergies to retrieve cloud macrophysical, } \\
\text { microphysical, and dynamic properties (Noel et al., 2002; } \\
\text { Chiriaco et al., 2004; Tinel et al, 2004). } \\
\text { - Application to large ground-based datasets and future satellite } \\
\text { missions }\end{array}$ & $x$ & $x$ & $x$ \\
\hline & $\begin{array}{l}\text { Representation of cloud properties in atmospheric models: } \\
\text { - Cloud microphysical properties in meso-scale models } \\
\text { - Cloud microphysical and dynamic properties in numerical } \\
\text { weather prediction models (European CloudNet project) }\end{array}$ & $x$ & $x$ & \\
\hline & $\begin{array}{l}\text { Photochemistry and clouds: } \\
\text { - Study of the representation of clouds and their impact on } \\
\text { photolysis in Chemistry-Transport models (Vautard et al., 2001) }\end{array}$ & $x$ & $x$ & \\
\hline & $\begin{array}{l}\text { Water vapour and clouds: } \\
\text { Water Vapour Profiling Inter-Comparison field experiment } \\
\text { (VAPIC) } \\
\text { - Ground and satellite remote sensing synergies to improve } \\
\text { water vapor retrievals } \\
\text { - Study of cloud formation processes (role of BL dynamics, water } \\
\text { vapor, and aerosols) of mid-latitude low-altitude clouds }\end{array}$ & $x$ & $x$ & $x$ \\
\hline & $\begin{array}{l}\text { Cloud overlap in GCMs: } \\
\text { - Exploiting radar-lidar synergies to derive new cloud overlap } \\
\text { assumptions for GCM sub-grid parametrizations. }\end{array}$ & $x$ & $x$ & \\
\hline & $\begin{array}{l}\text { Clouds and radiation in the regional climate: } \\
\text { - Regional climate study based on cloud and surface radiation } \\
\text { monitoring data. Detection of anthropogenic signals. }\end{array}$ & $x$ & $x$ & $\mathrm{x}$ \\
\hline & $\begin{array}{l}\text { Validation of satellite cloud property retrievals: } \\
\text { - Cloud height and thermodynamic phase retrieved by POLDER- } \\
1 \text { and POLDER-2 (Chepfer et al., 1999, 2000) } \\
\text { - Cloud top height retrieved by MISR and MODIS (Naud et al, } \\
\text { 2004) } \\
\text { - Semi-transparent clouds retrieved by SEVIRI/MSG }\end{array}$ & $\mathrm{X}$ & & $\mathrm{X}$ \\
\hline
\end{tabular}

radiative budget. In particular, the particles' size, shape and orientation in space have to be well documented in order to quantify correctly the ice cloud radiative impact. These properties vary widely from one situation to another, depending on the thermal and dynamic conditions under which the cloud was formed (e.g. jet cirrus, front cirrus, contrails). The following subsections describe the observation and interpretation tools developed at SIRTA to characterize cloud optical, microphysical and dynamical properties and ultimately to better understand the life cycle of clouds.

\subsubsection{Observing cirrus clouds}

Figure 4 shows a frontal passage observed by the RASTA radar (radar reflectivity, panel a) and the LNA lidar (lidar backscattered power, panel b) during $8 \mathrm{~h}$ on 1 April 2003. Both instruments show the typical evolution of the vertical distribution of clouds associated with mid-latitude fronts, characterized by optical-thin cirrus clouds ahead of the front followed by developing cumulonimbus clouds that eventually produce precipitation. Figure $4 \mathrm{c}$ shows a cloud mask derived from the combined analysis of the radar reflectivity and the lidar backscattered power. Clouds shown in yellow, green and red are detected by lidar only, radar only, and both instruments, respectively. Clouds shown in grey correspond to areas where one instrument detects clouds while the other detects cloud-free air. The cloud mask reveals that the lidar provides a full characterization of the vertical extent of the cirrus cloud (07:00 to 12:00 UT), but as the cloud becomes optically thicker, the lidar signal is attenuated and the range is limited to the lowest $2 \mathrm{~km}$ of the cloud. The cloud mask shows that the radar reflectivity can vary greatly in cirrus clouds ( -40 to $-20 \mathrm{dBZ}$ ), but becomes very strong 

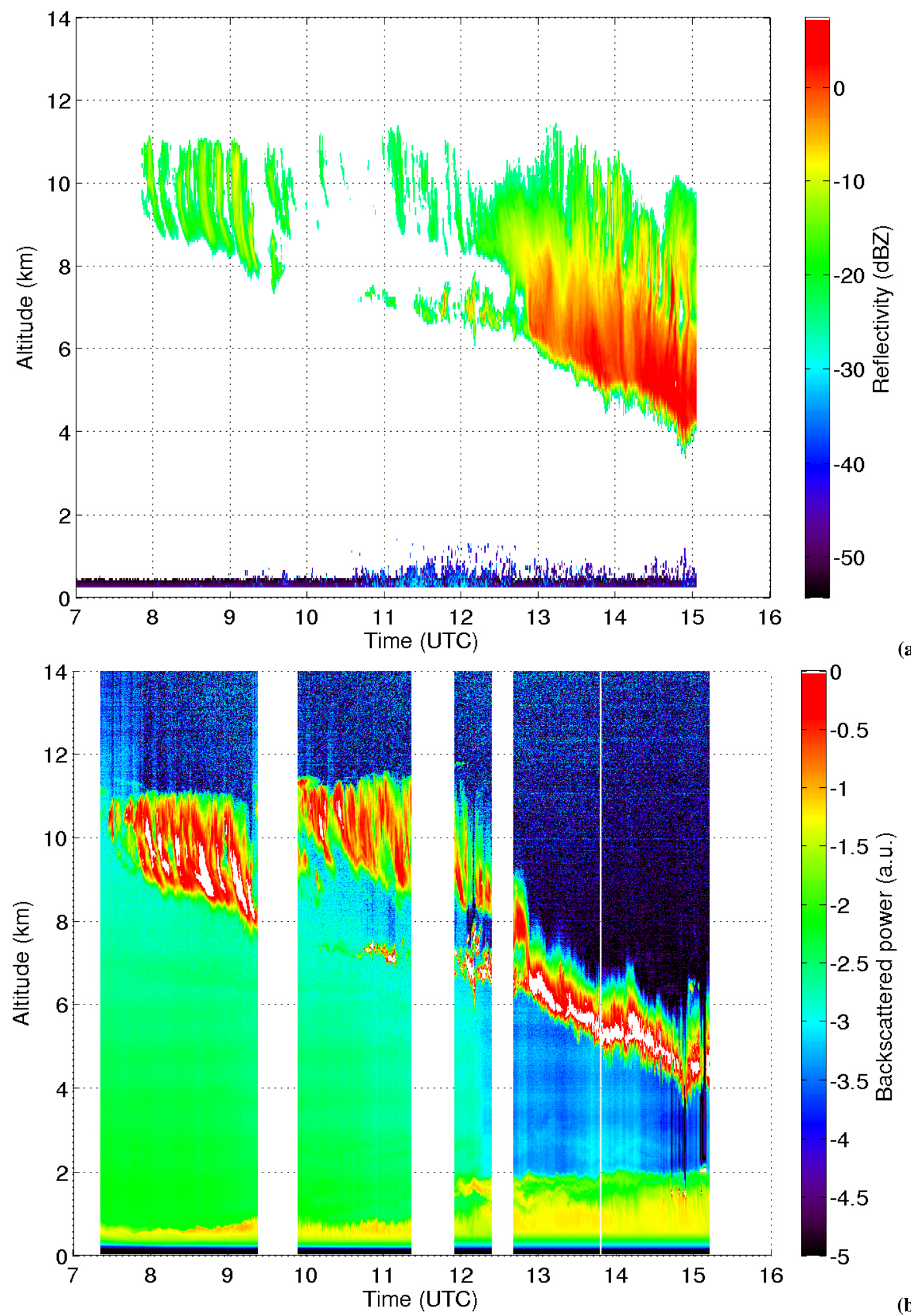

(a)

(b)

Fig. 4. Cloud layers observed at SIRTA on 1 April 2003. Vertical cross sections of (a) RASTA cloud radar reflectivity (dBZ), (b) LNA lidar backscattered power (proportional to $\mathrm{m}^{-1} \mathrm{sr}^{-1}$ ), (c) cloud mask derived from radar-lidar synergies (green: radar only; yellow: lidar only; red: radar+lidar retrieval; grey: discrepancy between lidar and radar retrieval; other: no cloud detected). 


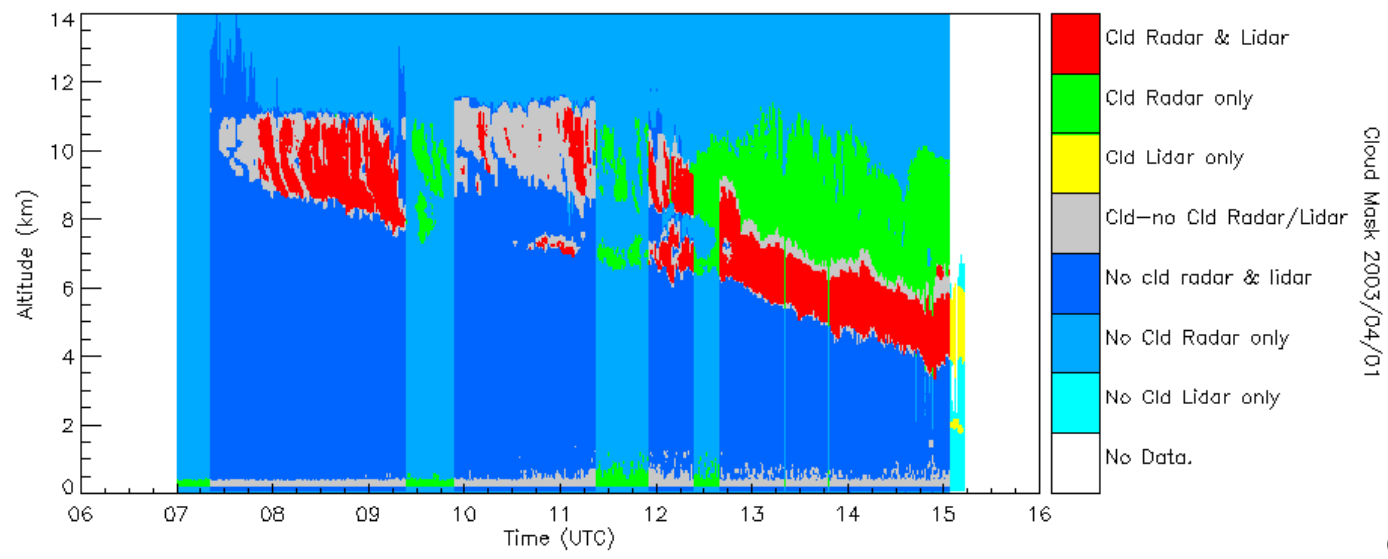

(c)

Fig. 4. Continued.

in mixed-phased or precipitating clouds (12:00-15:00 UT). Overlap of radar and lidar signals exist (red cloud mask) but the cloud mask reveals that radar-lidar synergy is particularly suited to extend the range of observable cloud layers.

\subsubsection{Cirrus cloud microphysical properties}

Infrared wavelengths are commonly used to retrieve particle size from satellite passive remote sensors, as those wavelengths are highly sensitive to the amount of ice present in the cloud. The classical split-window technique (Inoue, 1985), as well as more recent advanced techniques (Minnis et al., 1998; Baum et al., 2000; Platnick et al., 2003), are based on differences of absorption in various infrared channels, sometimes completed by visible channels. We use new retrieval techniques based on active and passive remote sensing synergies that will become available at the global scale with the future CALIPSO and CloudSat satellite missions.

- Vertical distribution of particle shape is retrieved from LNA lidar depolarization signals. This technique is based on the strong sensitivity of the state of polarization of the light in the visible domain to the shape of the scatterers. The light emitted by the laser of the lidar is initially linearly polarized, and the scattering by ice crystals changes the state of polarization of the light that is recovered by the lidar telescope. This sensitivity has been used for years (Sassen, 1991) for discriminating water clouds (spherical particles) and ice clouds (non-spherical crystals). We apply the algorithm developed by Noel et al. (2002) that will be used to process CALIPSO lidar data at the global scale. It uses lidar depolarization to classify the ice crystal shapes in four different categories, depending on their shape ratio Q, the ratio between the ice crystal length and width, ranging from plates (small Q) to columns (large Q). Shape ratio classes correspond to asymmetry factor intervals in the visible. The classification method uses simple comparisons between the measured linear depolarization rate and the simulated one for ice cloud composed of crystals with different shape ratios. The simulated lidar depolarization ratio is based on a ray-tracing code that includes multiple scattering phenomena. The comparison between the observed and simulated depolarization rate allows the variability of the ice crystal shape ratio $\mathrm{Q}$ within the cirrus cloud to be obtained.

Figure 5 shows the LNA lidar depolarization ratio, the cloud optical depth and particle shape classification for the case of 1 April 2003. In the cirrus cloud (before 12:00 UT) the depolarization ratio is greater than $50 \%$. It ranges between 15 and $30 \%$ at the base of the cumulonimbus cloud. The optical depth, derived from the attenuation of the LNA lidar backscattered power at cloud top compared to a theoretical return in the absence of the cloud (Cadet et al., 2004), is close to 1 in the cirrus cloud. Figure 5c shows that the cirrus cloud is predominantly constituted of columns, with flatter particles towards the base of the cloud. The base of the cumulonimbus cloud is formed of flat particles (plates). When depolarization is very low (less than 10\%) no particle shape is retrieved, indicating a possible mixedphase part of the cloud.

- Mean cloud layer particle size is retrieved with a split window technique improved by multi-wavelength retrieval constraints $(8.7,10.5$ and $12 \mu \mathrm{m})$ complemented by LNA lidar constraints: (i) cloud vertical range detection based on 532-nm backscattered lidar signal and (ii) shape constraint from 532-nm lidar depolarization. The lidar backscattered signal is used to detect the cirrus cloud, to determine its base and top altitude, and to estimate its top and base temperatures using an observed temperature profile. First, the IR radiances, combined with the lidar backscatter information, lead to several values of effective radius, depending on the particle shape hypothesis. Then, the lidar depolarization observation is used as a constraint in selecting the best guess for the particle shape ratio and hence the more reliable effective size. 

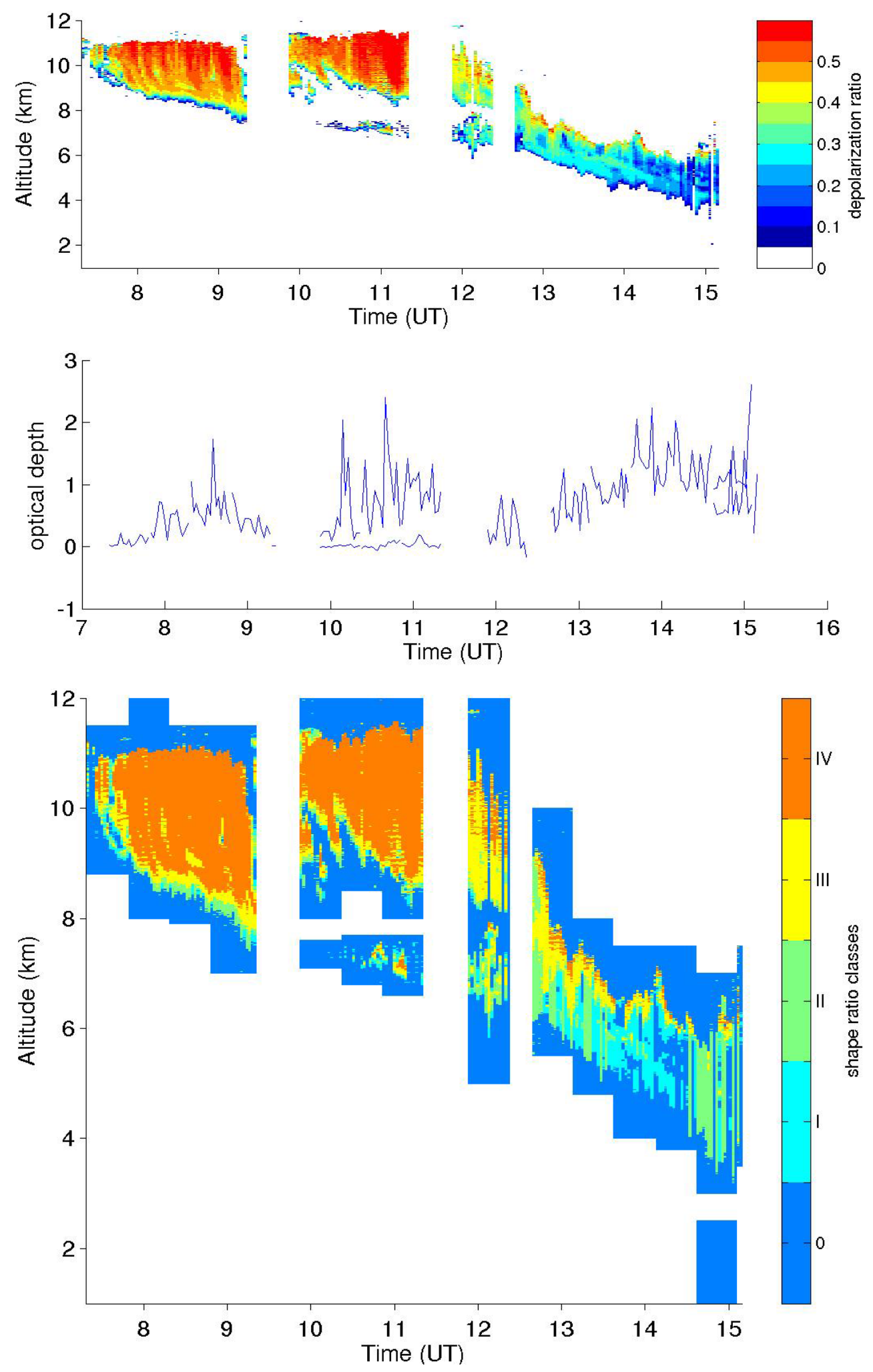

Fig. 5. Cloud properties observed on 1 April 2003: (a) LNA lidar depolarization ratio (ratio of cross-polarization to linear-polarization backscattered signal); (b) cloud layer optical depth; and (c) particle shape classification. Shape ratio classes: $\mathrm{I}=\mathrm{Q}<0.05$ (plates); $\mathrm{II}=0.05<\mathrm{Q}<0.7, \mathrm{III}=0.7<\mathrm{Q}<1.1 ; \mathrm{IV}=\mathrm{Q}>1.1$ (columns). 
For the 1 April 2003 case, the lidar-derived cloud base and top temperatures are $224 \mathrm{~K}$ and $214 \mathrm{~K}$, respectively, over a 1-h period centered on the Terra satellite overpass time (10:20 UT indicated by a vertical line in Fig. 4). The brightness temperature from the MODerate resolution Imaging Spectrometer (MODIS) on board Terra averaged over a $0.1^{\circ}$ region centered on SIRTA, is $242 \mathrm{~K}$. Retrievals based on three wavelength constraints yield particle sizes (effective radius) ranging from $8-57 \mu \mathrm{m}$. When the shape constraint is added the range of possible particle size is reduced to $11-35 \mu \mathrm{m}$.

The retrieval of the effective size by combination of infrared radiances and lidar (backscatter and depolarization) has been tested against twenty cases of ice clouds observed with the LNA lidar and the MODIS/TERRA infrared space-borne radiometer. The use of lidar data allows particle size for semi-transparent clouds to be retrieved and so extends the possible scope of application of the split-window technique to a wider number of cloud cases. Furthermore, the uncertainty on particle size retrievals is reduced between 20 and $65 \%$ when the shape constraint is used (Chiriaco et al., 2004).

The capability and limitations of this method are currently evaluated by comparing the results with in-situ observations from the Cirrus Regional Study of Tropical Anvils and Cirrus Layers - Florida Area Cirrus Experiment (CRYSTAL-FACE) and with multi-channel passive remote sensing techniques (Minnis et al., 1998) on a systematic basis during MODIS overpass on the SIRTA. This method will be applied to future CALIPSO lidar and infrared radiometer observations, and therefore provides particle size in semi-transparent cirrus clouds at the global scale.

- Cloud particle size and ice water content are derived from combined radar/lidar retrievals. As shown in previous studies (e.g. Intrieri et al., 1993), cloud radar and lidar observations carry complementary information on cloud properties, in particular, ice water content and effective radius. Direct methods that link the ratio of radar reflectivity to lidar extinction to the effective radius work well for optical depths less than 0.3, but assumptions are not satisfied for thicker clouds. New algorithms use the radar reflectivity to better constrain the lidar extinction retrieval (e.g. Donovan et al., 2001; Tinel et al., 2004). The algorithm developed by the CETP radar team uses a statistical relationship between lidar extinction and radar attenuation derived from a large set of in-situ microphysical observations. It is well known that the cloud-to-cloud variability of the particle size distribution (PSD) is high. However, Testud et al. (2001) showed that for precipitating events the shape of the PSD is roughly invariant when normalizing the diameter axis by the mean diameter of the distribution, that is, the number concentration can be expressed as

$N(D)=N_{0} * F(D / D m)$, where $D$ is the particle diameter, $D m$ is the mean diameter of the distribution, and $N_{0}^{*}$ is the intercept parameter of the PSD. If the shape of the distribution is fixed, all the variability of the PSD is contained in $N_{0}^{*}$. This normalization concept has been applied to non-precipitating ice clouds by processing very large in-situ microphysical data-sets both in the tropical and mid-latitude regions, in the Northern and Southern Hemispheres (e.g. the Fronts and Atlantic StormTrack Experiment, FASTEX; the Central Equatorial Pacific Ocean Experiment, CEPEX; the European cloud radar and lidar experiments CLARE-1998, CARL-2000 and CARL-2001). The shape of the normalized PSD is found to be roughly invariant for non-precipitating ice clouds (Delanoë et al., 2005 ${ }^{1}$ ). As a result, statistical relationships between moments of the normalized PSD are also found to be invariant. The n-th moment of the PSD is defined as

$M(n)=\int N(D)^{D^{n}} d D$,

where $N(D)$ is the PSD. Since lidar extinction and radar attenuation are proportional to the second and first moments of the PSD, it implies that a "universal" statistical relationship parameterized by $N_{0} *$ can be derived as

$\alpha=\mathrm{a}_{0}^{* 1-b} \mathrm{~K}^{\mathrm{b}}$,

where $\mathrm{a}$ and $\mathrm{b}$ are the parameters of the relationship, $\alpha$ is the lidar extinction and $\mathrm{K}$ is the radar attenuation (Delanoë et al., 2005 ${ }^{1}$ ). $N_{0}^{*}$ becomes an unknown to be retrieved by the radar-lidar algorithm. This algorithm has been validated through dedicated airborne campaigns during the European CARL program, using the airborne RALI radar-lidar system (Protat et al., 2004) flying above the clouds, and airborne in-situ microphysical measurements within the cloud (Tinel et al. 2004).

The radar-lidar algorithm has been applied to the cloud depth seen by the two instruments on 1 April 2003, shown in Fig. 4. Figures 6a, b, c, d show the lidar extinction, ice water content, effective radius, and $N_{0}^{*}$, respectively. The vertical distribution of the cloud properties is interesting in this case, with ice water content increasing, effective radius decreasing, and $N_{0}^{*}$ increasing with height. The increase in effective radius when approaching the cloud base likely reflects the importance of the aggregation/coalescence processes when cloud particles sediment within the cloud. This is consistent with the retrieved decrease of $N_{0}^{*}$ when approaching the cloud base, that can be interpreted as a decrease in number of the smaller cloud particles and then as an occurrence of aggregation. The smaller ice water contents

\footnotetext{
${ }^{1}$ Delanoë, J., Protat, A., Testud, J., and Bouniol, D.: Statistical properties of the normalized ice particle size distribution, J. Geophys. Res., under revision, 2004.
} 

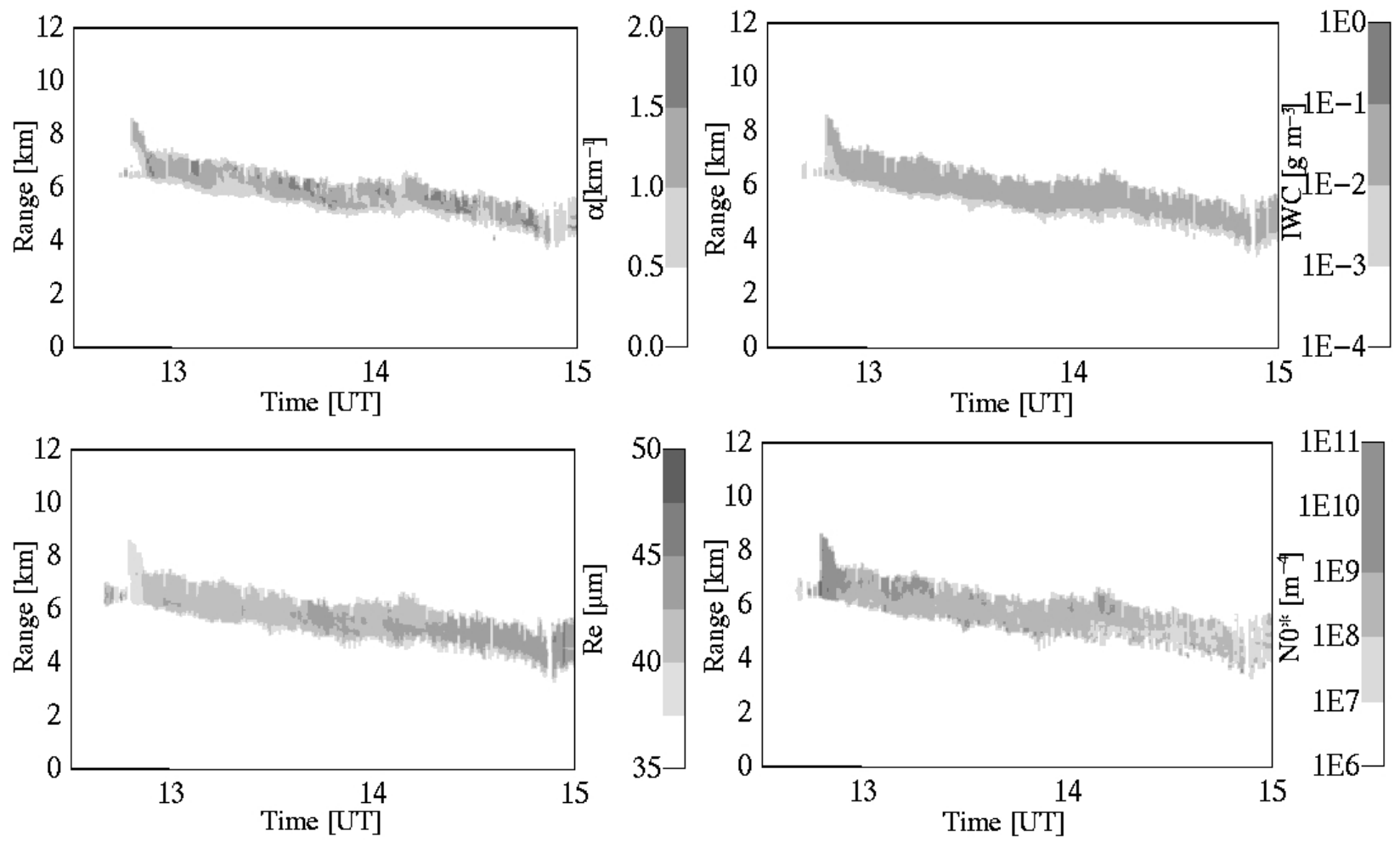

Fig. 6. Cloud microphysical properties retrieved from the radar-lidar algorithm on 1 April 2003: (a) lidar extinction coefficient $\left(\mathrm{km}^{-1} \mathrm{sr}^{-1}\right)$, (b) ice water content $\left(\mathrm{gm}^{-3}\right)$, (c) particle effective radius $(\mathrm{mm}),(\mathbf{d})$ intercept of particle size distribution $\mathrm{No}^{*} .\left(\mathrm{m}^{-4}\right)$.

at cloud base are likely associated with strong evaporation occurring there. Presently, this algorithm is being implemented as a routine algorithm, in order to run continuously on the CloudNet data set and prepare its integration for the automated processing of the future space-borne observations from CALIPSO and CloudSat).

\subsubsection{Cirrus cloud dynamical properties}

In operational forecast and climate models the life cycle of a cloud is strongly linked to its internal dynamics (sedimentation of cloud particles), to the environmental air dynamics (wind) and to the feedbacks between dynamics and microphysics, that is, to the way the effective radius and water content is modified by the internal cloud dynamics and viceversa. In a model this essentially translates into two dynamic parameters that must be accurately represented: the terminal fall speed of the cloud particles and the vertical air velocity. Vertically-pointing cloud radars measure the sum of vertical air velocity $\mathrm{w}$ and terminal fall velocity $\mathrm{V}_{T}$. In order to separate these two components, statistical approaches have been proposed (Orr and Kropfli, 1999; Protat et al., 2002; Protat et al., 2003), assuming that for a long time span the mean vertical air motion should vanish with respect to the mean terminal fall velocity that is much less fluctuating. A statistical power-law relationship between the terminal fall speed and radar reflectivity may therefore be derived using this assumption. $\mathrm{V}_{T}$ can then be subtracted from the Doppler velocity to access the vertical air velocity component.

The retrieval of cloud dynamics is illustrated in Fig. 7, which shows the retrieved terminal fall velocity and vertical air velocity for the 1 April 2003 case. Terminal fall velocities range between 0 and $-1.0 \mathrm{~m} / \mathrm{s}$, which are realistic values for this type of cloud. In the cirrus part of the cloud (07:00-12:00 UT) particles fall in the fall streaks at about $0.5 \mathrm{~m} / \mathrm{s}$ and about half that velocity outside the fall streaks. The effect of aggregation is shown in the cumulonimbus part of the cloud (13:00-15:00 UT), with fall velocities in excess of $1.0 \mathrm{~m} / \mathrm{s}$ in the lowest part of the cloud. Figure $7 \mathrm{c}$ reveals positive vertical air velocities close to the cloud top, ranging between +0.5 and $+1.0 \mathrm{~m} / \mathrm{s}$. These updrafts allow particles to reside and grow by vapour deposition. At the top of the cumulonimbus cloud high frequency ascendance and subsidence structure $(+/-1 \mathrm{~m} / \mathrm{s})$ reflects the turbulent nature of the dynamics near cloud edges.

The method used here generally works very well for thin clouds, such as cirrus clouds. However, it is also observed that a single $\mathrm{V}_{T}$-reflectivity relationship cannot, in some cases, be derived to represent accurately the whole cloud depth, especially when the cloud depth increases, owing to changes in the cloud microphysics as the crystals fall within the cloud layer (e.g. aggregation which tends to produce less and less dense cloud ice particles). Truncating the cloud 

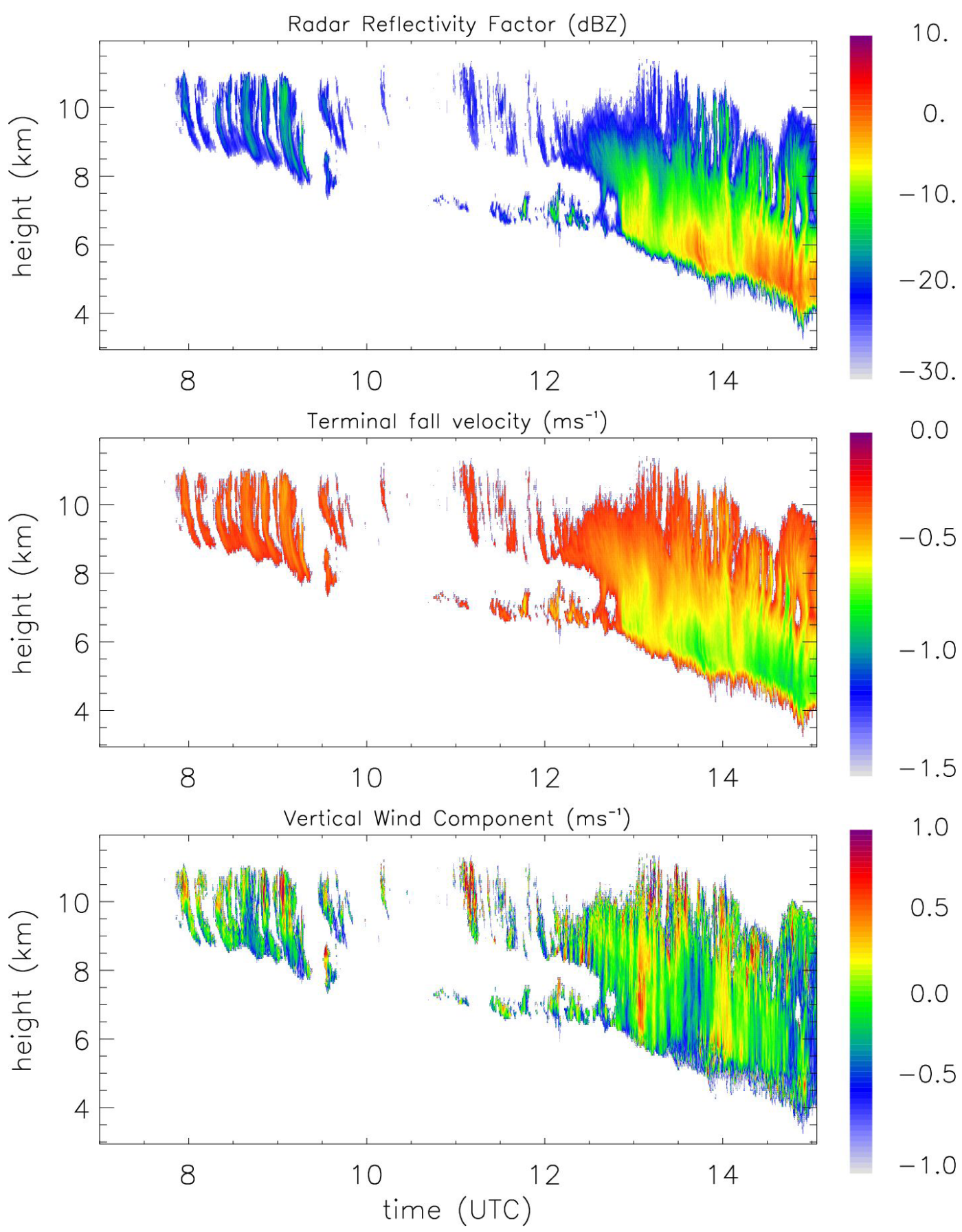

Fig. 7. Dynamical properties of the cloud layers observed at SIRTA on 1 April 2003: (a) RASTA radar reflectivity (dBZ), (b) particle terminal fall velocity $\left(\mathrm{m} \mathrm{s}^{-1}\right)$ and (c) air vertical velocity $\left(\mathrm{m} \mathrm{s}^{-1}\right)$.

in several layers and applying the same statistical approach leads to an increase in the statistical error of the $\mathrm{V}_{T}$ estimates (Orr and Kropfli, 1999). Therefore, to improve the $\mathrm{V}_{T}$ estimate, we are investigating the use of lidar information as an additional constraint to the problem. As described in Sect. 4.2.2 (and in Noel et al., 2002), the lidar depolarization ratio carries quantitative information on particle shape (ratio of the crystal length to the diameter of its hexagonal base) under some assumptions. The next step of this study is to establish an individual Vt-reflectivity relationship for each class of particle shape, which should limit the impact of a change in cloud microphysics as a function of cloud depth.

\subsection{Boundary-layer cloud case study}

Representation of turbulent and mesoscale transport in the planetary boundary layer (PBL) is an important issue for climate modeling, in particular for determination of 

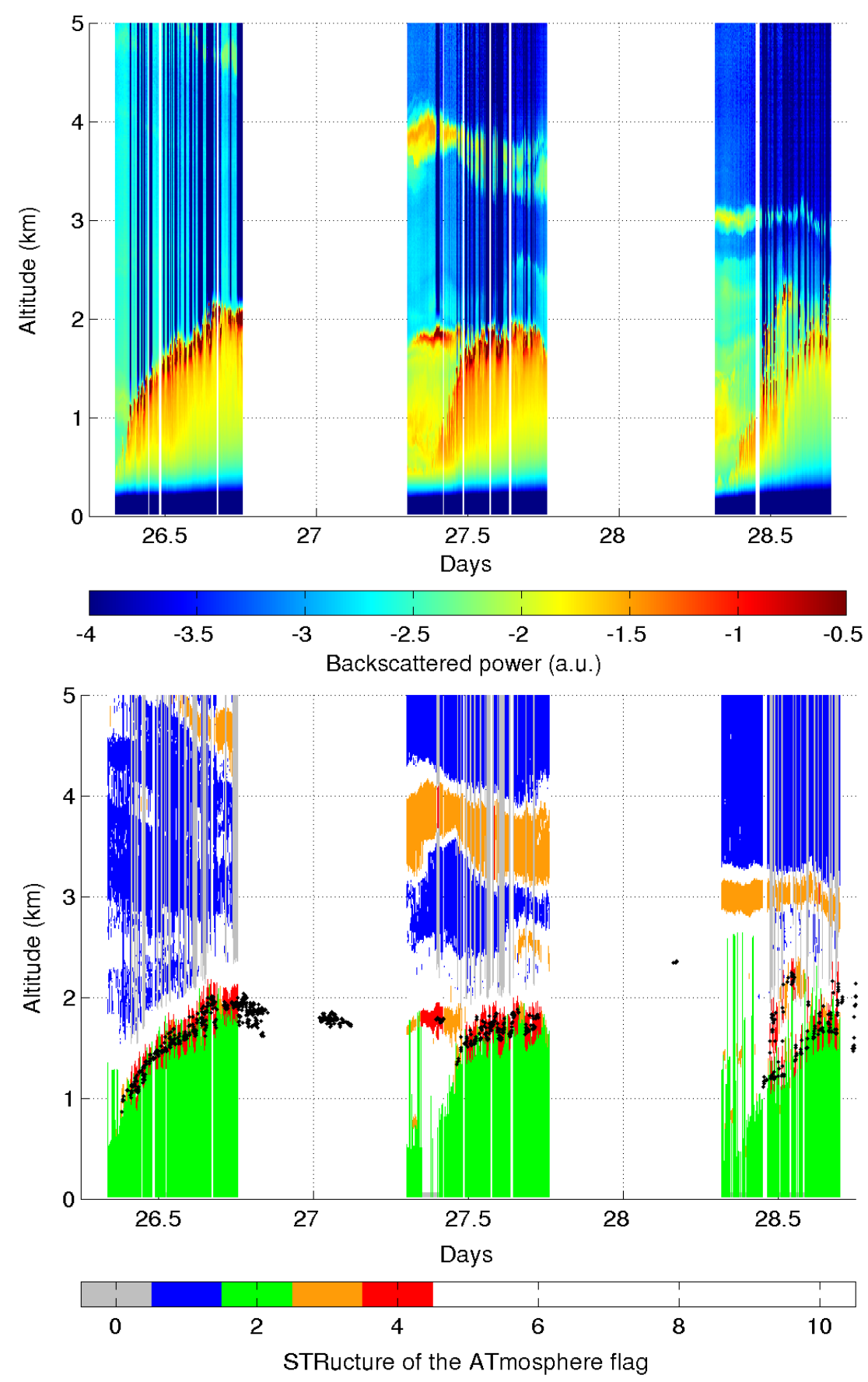

Fig. 8. Clouds and aerosols observed during the 26-28 May 2003 period. (a) Range-corrected backscattered lidar signal. Clouds at the top of the boundary layer appear in red (strongest backscattering). A persisting aerosol layer drops from 6 to $3 \mathrm{~km}$ from 26 to $28 \mathrm{May}$. (b) Vertical structure mask of the atmosphere derived from 532-nm lidar backscattering signal. The boundary-layer height is shown in green, aerosol and cloud layers are labeled in orange and red, respectively. Black dots show cloud base height retrieved by ceilometer. Particle-free layers are shown in blue.

biosphere-atmosphere exchanges and for prediction of cloud cover. The fundamental features of the PBL dynamics are its diurnal evolution and its turbulent nature (Stull, 1988). At night a stably stratified boundary layer lies below a residual layer (RL). During daytime, strong turbulence mixing occurs in the convective boundary layer (CBL). In the CBL, the vertical mixing is non local as opposed to the surface layer, i.e. mesoscale structures, such as thermals, convective PBL cells or rolls, transport most of the energy at the various vertical levels (e.g. Emanuel, 1991). In the following case study we present a method that confronts observations of boundary layer parameters to diagnostic-performed outputs from a 
global circulation model. The ability of the model to represent physical processes can be assessed by analysing a large number of situations.

\subsubsection{Observing boundary layer processes}

Figure $8 \mathrm{a}$ shows three consecutive convective situations above SIRTA observed by the LNA lidar on 26, 27, and 28 May 2003. On 26 May a persistent layer of fair weather cumulus clouds appears at 10:00 UT; it prevents rapid growth of the boundary layer. Maximum boundary layer height, about $2000 \mathrm{~m}$, is reached around 16:00 UT. On 27 May a residual layer and fewer clouds favour a more rapid growth of the convective boundary layer than the previous day. In the early morning, the developing boundary layer can entrain energy and matter from the residual layer, contributing to its growth (Fochesatto et al., 2001). Even fewer clouds form on 28 May but fair weather cumuli appear at multiple levels. The boundary layer becomes decoupled around 12:00 UT.

The algorithm developed by Morille et al. (submitted, 2004) ${ }^{2}$ (see Sect. 3.1) is applied to the LNA lidar data. The vertical structure mask of the atmosphere produced for the 26-28 May period is shown in Fig. 8b. The boundary layer is identified in green, cloud and aerosol layers are shown in red and orange, respectively, and particle-free layers are coloured in blue. Grey areas indicate where the lidar signal is optically attenuated. Black dots represent cloud base height retrieved by the ceilometer algorithm. On 26 May 2003, the lidar signal is attenuated intermittently by optically dense boundary layer clouds. Lidar and ceilometer cloud occurrence retrievals are in agreement. On 27 May 2003, the top of the green layer is actually the top of the residual layer until the boundary layers starts to develop around 9:30 UT. At this point the gradient between the boundary and residual layers becomes strong enough for the algorithm to separate them. On 28 May 2003, the complex nature of the boundary layer, with alternating cloud and cloud-free situations, is well captured by the algorithm. Lidar-based cloud occurrence detection is in good agreement with the ceilometer cloud-base retrieval. The products shown in Fig. $8 \mathrm{~b}$ are very useful tools both for analysis of case studies and statistical analysis of large data sets.

\subsubsection{Modelling boundary-layer processes in global circu-} lation model

LMDZ is the atmospheric global circulation model originally developed at LMD and used at IPSL for climate studies (e.g. Sadourny and Laval, 1984). The dynamical core is based on finite difference formulation of the primitive equations of meteorology. The equations are discretised on the sphere on a stretchable longitude-latitude grid, allowing for finer resolution on a particular region of the globe. Coupled to the dynamical core, the model includes a set

\footnotetext{
${ }^{2}$ Morille, Y., Haeffelin, M., Drobinski, P., and Pelon, J.: STRAT: STRucture of the ATmosphere retrieved from single channel lidar data, J. Atmos. Oceanic. Tech., submitted, 2004.
}

of physical parametrisations for radiative transfer in the solar (Fouquart and Bonnel, 1980) and thermal infrared (Morcrette et al., 1986) ranges, cumulus convection (Emanuel, 1991) and clouds (Le Treut and Li, 1991; Bony and Emanuel, 2001). Evaporation is based on a simple bucket model and is computed as a function of near surface humidity and humidity at saturation for a given surface temperature. Turbulent vertical transport is represented by a thermal plume model (Hourdin et al., 2002). This mass flux parameterization of the convective boundary layer replaces the counter-gradient term introduced in the original K-diffusion formulation, plus a dry convective adjustment used in the model to prevent unstable temperature profiles to occur.

For comparison with SIRTA observations, the model is run with a refined grid over the Paris area. In this study we use a version based on a global grid of only 48 points in longitude and 32 in latitude, zoomed to reach a $100-\mathrm{km}$ resolution over France. Model variables are relaxed toward NCEP analysis (nudging technique) to force the large-scale synoptic circulation. The nudging scheme is defined as

$d X / d t=(d X / d t)_{G C M}+\left(X_{a n}-X\right) / \tau$,

where $X$ is the vector of model variables, $X_{a n}$ the corresponding values from the analysis, $(d X / d t)_{G C M}$ the tendency computed by the general circulation model and $\tau$ is a time constant. The time constant $\tau$ varies from one half hour outside the zoom area to obtain a realistic large-scale synoptic situation, to 10 days inside the zoom area to allow the model to compute its own meteorology. The grid and the associated relaxation time constant are shown in Fig. 9. Next, we use SIRTA observations to assess the parameterizations of the general circulation model, in particular those of the thermal plume model.

\subsubsection{Assessing boundary layer parametrizations}

In order to detect conditions suitable for a physical study of surface driven boundary layer processes using model output, we use the diagnostic of the boundary layer height $(\mathrm{BLH})$ based on a method proposed by Troen and Mahrt (1986) with extensions by Holstlag and Boville (1993). The physics behind the algorithm is that, under unstable situations, some parcels of air (characterized by an excess of buoyancy) can detach from the surface layer and rise until an equilibrium level is reached. This level is taken as the BLH. Then, the lifting condensation level (LCL) of the parcel virtually lifted from near the surface is compared to the BLH. If the LCL is lower than the BLH, the LCL should correspond to the base height of a boundary-layer cloud resulting from surface driven processes. If the LCL coincides with the observed cloud-base height, one may assume that the processes inducing BL clouds are local or are created in an area with similar air mass and ground characteristics (quasi-Lagrangian case) as the area of study. In such a situation, both largescale fields and surface conditions are deemed to force the boundary layer in a realistic manner. In addition, observed temporal variations can be interpreted as the evolution of a 


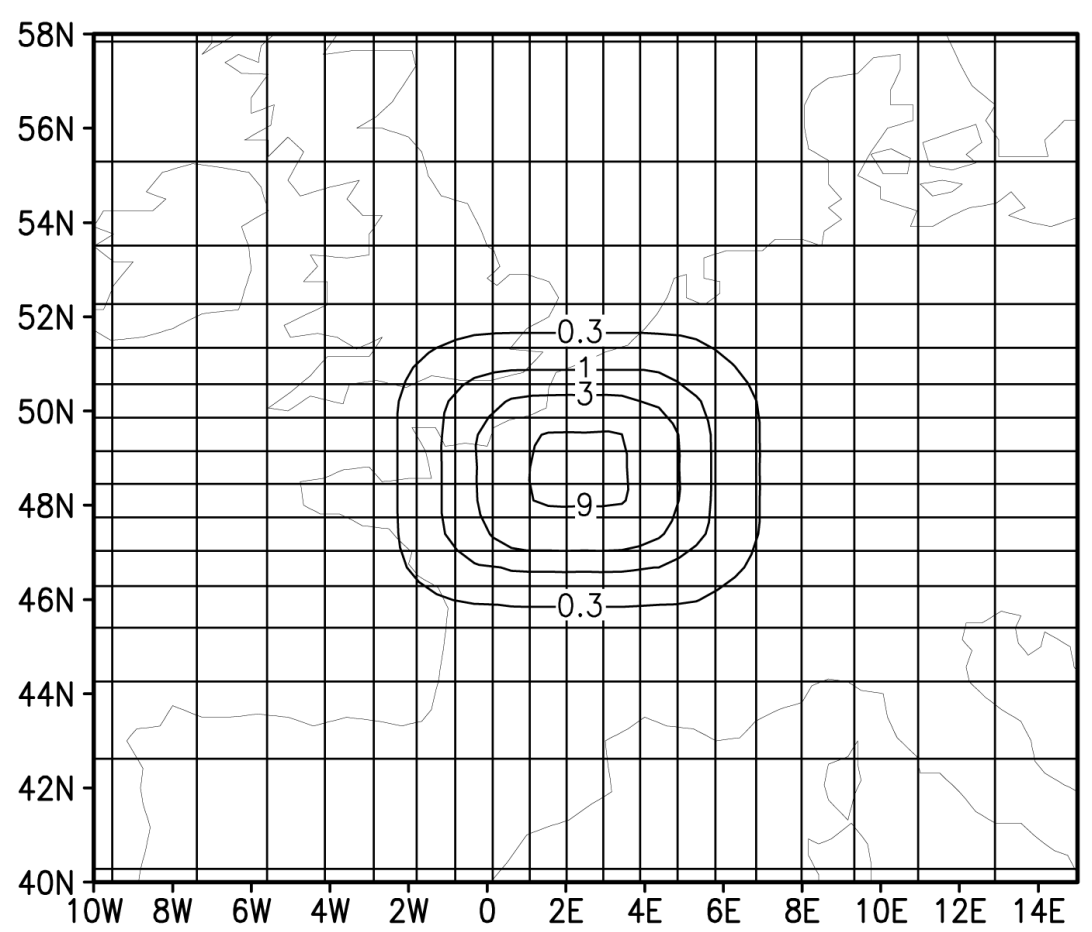

Fig. 9. Grid used in SIRTA simulations with LMDZ. The rectangles show the mesh zoomed on SIRTA. The contours correspond to relaxation time constants for nudging.

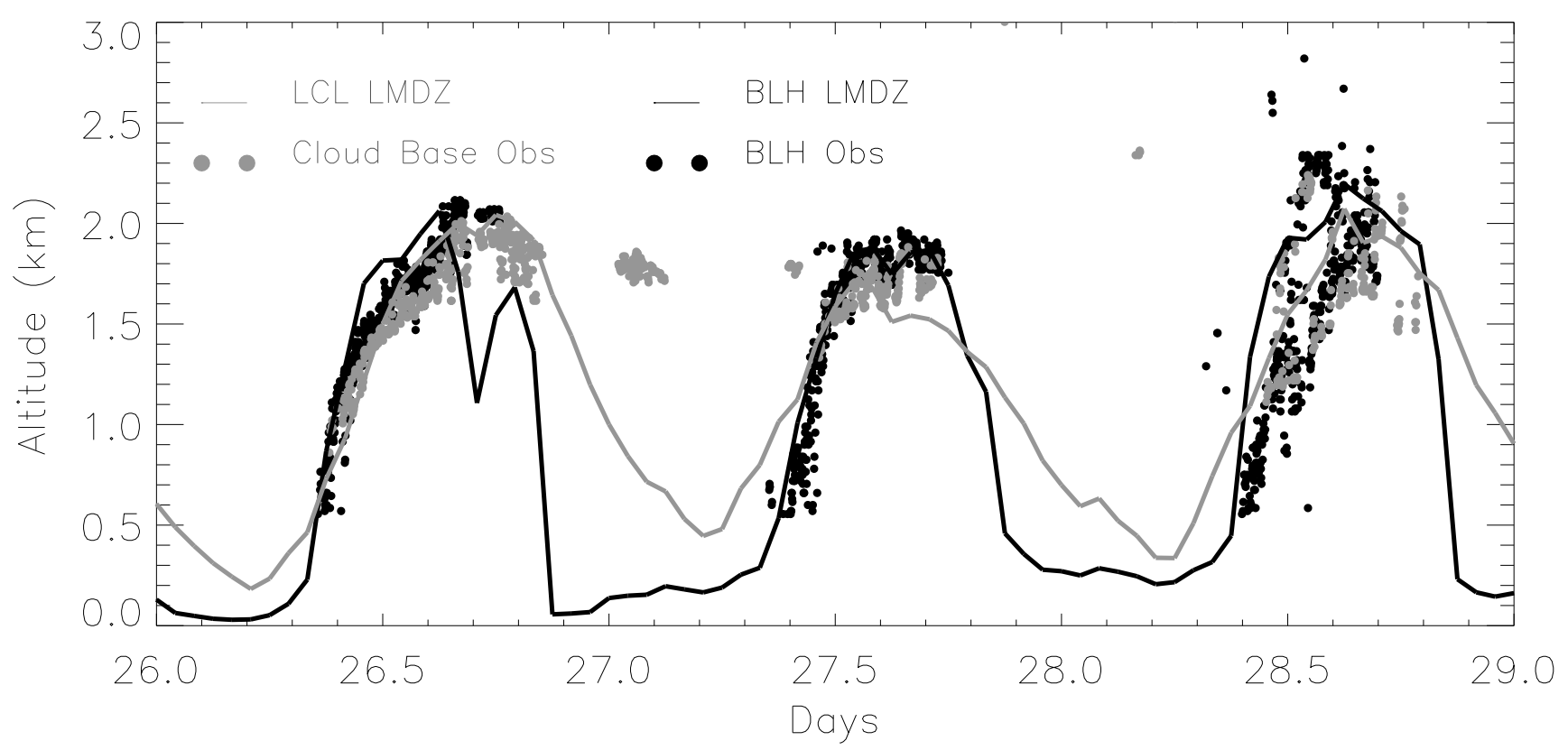

Fig. 10. Evolution of the first cloud base height (grey) and boundary layer height (black). Dots are lidar and ceilometer observations. Solid lines are diagnostics based on LMDZ runs. Three diurnal cycles are represented (26-28 May 2003).

consistent air mass. When no agreement between model and observations is found, one must look at complementary observations to identify the source of discrepancy.

We compare boundary layer heights and lifting condensation levels diagnosed from LMDZ output to boundary layer heights retrieved by the LNA lidar and cloud base heights derived from ceilometer data, respectively, for the 26-28 May 2003 period described previously. The 26-28 May 2003 period is selected because it shows well-developed cases of convective boundary layers topped with cumulus clouds. 
Figure 10 shows diurnal cycles of the modelled and observed boundary layer parameters. The shapes and amplitudes of the boundary layer diurnal cycles are well captured by the diagnostics over the entire period. In addition, situations where the model is able to create boundary layer clouds, revealed by an LCL below the BLH, are in phase with observed fair weather cumulus clouds. On 28 May we observe multiple cloud layers, characteristic of a complex situation and a decoupled boundary layer. Model diagnostics match the higher observed cloud and boundary layers.

Such conditions are well suited to assess and develop further the LMDZ thermal plume model. Lidar backscattering profiles may be used to validate model internal variables, such as the relative fraction of up-drafts, the height reached by thermals and the thickness of the entrainment layer, and if possible, vertical velocities. Clouds must also be included in this convective model developed originally for the dry convective boundary layer. This approach has been used to assess simultaneously the BLH and LCL, the cloud fraction and cloud radiative forcing in two numerical weather prediction models (Mathieu et al., submitted, 2004 ${ }^{3}$ ).

\section{Conclusions}

SIRTA is an atmospheric observatory based on a growing ensemble of state-of-the-art active and passive remote sensing instruments. SIRTA was developed following a new concept in atmospheric sciences of instrument facilities that gather and collaboratively manage remote sensing capabilities from a large number of institutes, research laboratories and private industry. Today, the SIRTA observatory operates active and passive remote sensors on a routine basis to profile the atmosphere from ground to $15 \mathrm{~km}$. An extensive database containing four years of cloud and aerosol lidar data and two years of cloud radar data already exists and is accessible to the scientific community.

Research activities at SIRTA focus on processes and properties in the life cycle of clouds from the boundary layer to the free troposphere, taking advantage of the instrument synergies offered. It appears clearly from our initial exploitation of the SIRTA database that the complementary capabilities of radar and lidar measurements are very valuable contributions to study the large range of ice and mixed-phased clouds that occur over mid-latitude continents. The availability of these ground-based active remote sensing data is also necessary to prepare and ensure the success of future satellite missions. Further, we illustrate how observation data are used to identify situations that are suited to evaluate the ability of atmospheric models to simulate physical processes. This is the first step towards improving parametric representations of sub-scale processes.

\footnotetext{
${ }^{3}$ Mathieu, A., Piriou, J.-M., Haeffelin, M., Drobinski, P., Vinit, F., and Bouyssel, F.: Identification of error sources in planetary boundary layer cloud forecast using SIRTA observations, Geophys. Res. Lett., submitted, 2004.
}

Future work at SIRTA consists of extending the application of level-2 algorithms described in this paper to the entire database. This will enable researchers to perform statistical analyses of the observed cloud and aerosol properties. Future developments will also focus on enhancing the model-to-observation comparison methods by, for example, simulating radar and lidar observables directly from model output, and exploiting ground and satellite synergies to better describe the large-scale conditions in which smaller-scale processes take place.

Acknowledgements. The authors would like to acknowledge P. H. Flamant and C. Loth, the founding fathers of SIRTA, whose vision and hard work resulted in the establishment of the observing infrastructure. We wish to acknowledge C. Basdevant and G. Mégie, the directors of LMD and IPSL, respectively, at the time SIRTA was established. The authors would like to thank the Centre National d'Etudes Spatiales (CNES), Ecole Polytechnique, Institut National des Sciences de l'Univers - Centre National de la Recherche Scientifique (INSU - CNRS), and Institut Pierre Simon Laplace for their recurrent support of the SIRTA observatory. Financial support has been provided by the EU CloudNET action contract EVK2-200000065 .

Topical Editor O. Boucher thanks a referee for her/his help in evaluating this paper.

\section{References}

Ackerman, T. and Stokes, G.: The Atmospheric Radiation Measurement Program, Physics Today, 56, 38-45, 2003.

Ansmann, A., Bösenberg, J., Chaikovsky, A., Comerón, A., Eckhardt, S., Eixmann, R., Freudenthaler, V., Ginoux, P., Komguem, L., Linné, H., López Márquez, M. A., Matthias, V., Mattis, I., Mitev, V., Müller, D., Music, S., Nickovic, S., Pelon, J., Sauvage, L., Sobolewsky, P., Srivastava, M. K., Stohl, A., Torres, O., Vaughan, G., Wandinger, U., and Wiegner, M.: Long-range transport of Saharan dust to northern Europe: The 11-16 October 2001 outbreak observed with EARLINET, J. Geophys. Res., Vol. 108, No. D24, 4783, doi:10.1029/2003JD003757, 2003.

Baum, B. A., Kratz, D. P., Yang, P., Ou, S.C., Hu, Y., Soulen, P. F., and Tsay, S.C.: Remote sensing of cloud properties using MODIS Airborne Simulator imagery during SUCCESS I. Data and models, J. Geophys. Res., 105, 11 767-11 780, 2000.

Bastin, S., Drobinski, P., Dabas, A. M., Delville, P., Reitebuch, O., and Werner, C.: Impact of the Rhône and Durance Valleys on Sea-Breeze Circulation in the Marseille Area, Atmos. Res., in press, 2005.

Bony, S. and Emanuel, K.: A parameterization of the cloudiness associated with cumulus convection; evaluation using TOGA COARE data, J. of Atmos. Sci., 58 (21), 3158-3183, 2001.

Bony, S., Dufresne, J.-L., Le Treut, H., Morcrette, J.-J., and Senior, C.: On dynamic and thermodynamic components of cloud changes, Climate Dynamics, 22, 71-86, 2004.

Cadet, B., Giraud, V., Haeffelin, M., Keckhut, P., Rechou, A., and Baldy, S.: Improved retrievals of cirrus cloud optical properties using a combination of lidar methods, Appl. Optics, in press, 2005.

Chepfer, H., Goloub, P., Sauvage, L., Flamant, P. H., Brogniez, G., Spinhirne, J., Lavorato, M., and Sugimoto, N.: Validation of POLDER/ADEOS data using a ground-based lidar network: pre- 
liminary results for semi-transparent clouds, Physics and Chemistry of the Earth, 24, 203-206, 1999.

Chepfer, H., Goloub P., Spinhirne, J., Flamant, P. H., Lavorato, M., Sauvage, L., Brogniez, G., and Pelon, J.: Cirrus clouds properties derived from POLDER-1/ADEOS polarized radiances: First validation using a ground-based lidar network, J. Appl. Meteo., 39, 154-168, 2000.

Chiriaco, M., Chepfer, H., Noel, V., Delaval, A., Haeffelin, M., Dubuisson, P., and Yang, P.: Improving retreivals of cirrus cloud particle size coupling lidar and three-channel radiometric techniques, Monthly Weather Review, 32, 1684-1700, 2004.

CloudNet Project, URL: http://www.met.rdg.ac.uk/radar/cloudnet/.

Donovan, D. P., Van Lammeren, A. C. A. P., Hogan, R. J., Russchenberg, H. W. J., Apituley, A., Francis, P., Testud, J., Pelon, J., Quante, M., and Goddard, J.: Cloud effective particle size and water content profile retrievals using combined lidar and radar observations, Part 2: Comparison with IR radiometer and in situ measurements of ice clouds, J. Geophys. Res., 106, 27449 27 464, 2001.

Drobinski, P., Haeberli, C., Richard, E., Lothon, M., Dabas, A. M., Flamant, P. H., Furger, M., and Steinacker, R.: Scale Interaction Processes during MAP-IOP 12 South Foehn Event in the Rhine Valley, Quart. J. Roy. Meteorol. Soc., 129, 729-754, 2003.

Drobinski, P., Dabas, A., and Flamant, P. H.: Remote Measurement of Turbulent Wind Spectra by Heterodyne Doppler Lidar Technique, J. Appl. Meteorol., 39, 2434-2451, 2000.

Drobinski, P., Brown, R. A., Flamant, P. H., and Pelon, J.: 1998: Evidence of organised large eddies by ground-based Doppler lidar, sonic anemometer and sodar, Boundary Layer Meteorol., 88, 343-361, 1998.

Dupont, E., Menut, L., Carisssimo, B., Pelon, J., and Flamant, P.: Comparison between the atmospheric boundary layer in Paris and its rural suburbs during the ECLAP experiment, Atmos. Environ. 33, 979-994, 1999.

Elouragini, S. and Flamant, P. H.: Iterative method to determine an averaged lidar ratio and the range resolved extinction in cirrus, Appl. Opt., 35, 1512-1518, 1996.

Emanuel, K. A.: A scheme for representing cumulus convection in large-scale models. J. Atmos. Sci., 48, 2313-2335, 1991.

Eymard, L.: Analysis of cloud liquid water content characteristics from SSMI anda shipborne radiometer, in: Microwave Radiometry and Remote Sensing of the Earth's Surface and Atmosphere, edited by Pampaloni, P. and Paloscia, S., VSP Int. Science Publishers, 235-245, 2000.

Fochesatto, J., Drobinski, P., Flamant, C., Guédalia, D., Sarrat, C., Flamant, P. H., and Pelon, J.: Evidence of dynamical coupling between the residual layer and the developing convective boundary layer, Boundary Layer Meteorol., 99, 451-464, 2001.

Fouquart, Y. and Bonnel, B.: Computations of solar heating of the Earth's atmosphere: A new parametrization, Contrib. Atmos. Phys., 53, 35-62, 1980.

Guichard, F., Parsons, D., Duhdia, J., and Bresch, J.: Evaluating mesoscale model predictions of clouds and radiation with SGP ARM data over a seasonal timescale, Mon. Wea. Rev., 131, 926944, 2003

Han, Y. and Westmaster, E. R.: Analysis and improvement of tipping calibration for ground-based microwave radiometers, IEEE transasctions on geoscience and remote sensing, vol. 38, 3, 1260-1276, 2000.

Hodzic, A., Chepfer, H., Vautard, R., Chazette, P., Beekmann, M., Bessagnet, B., Chatenet, B., Cuesta, J., Drobinski, P., Goloub, P., Haeffelin, M., Morille, Y.: Comparison of aerosol chemistry transport model simulations with lidar and Sun photometer observations at a site near Paris, J. Geophys. Res., 109, D23201, doi:10.1029/2004JD004735, 2004.

Hogan, R. J., Bouniol, D., Ladd, D. N., O'Connor, E. J., and Illingworth, A. J.: Absolute calibration of $94 / 95-\mathrm{GHz}$ radars using rain, J. Atmos. Oceanic Tech., 20(4), 572-580, 2003.

Hogan, R. J. and Illingworth, A. J.: Parameterizing ice cloud inhomogeneity and the overlap of inhomogeneities using cloud radar data, J. Atmos. Sci., 60(5), 756-767, 2002.

Holben, B. N., Eck, T. F., Slutsker, I., Tanre, D., Buis, J. P., Setzer, A., Vermote, E., Reagan, J. A., Kaufman, Y. J., Nakajima, T., Lavenu, F., Jankowiak, I., and Smirnov, A.: AERONET-A federated instrument network and data archive for aerosol characterization, Remote Sensing of Environment, 66, (1), 1-16, 1998.

Holtslag, A. A. M. and Boville, B. A.: Local versus nonlocalboundary-layer diffusion in a global climate model, J. Climate, 6, 1825-1842, 1993.

Hourdin, F., Couvreux, F., and Menut, L.: Parametrization of the dry convective boundary mayer based on a mass flux representation of thermals, J. Atmos. Sci., 59, 1105-1123, 2002.

Intrieri, J. M., Stephens, G. L., Eberhard, W., and Uttal, T.: A method for determining cirrus cloud particle sizes using a lidar and radar backscatter technique. J. Appl. Meteor., 32, 1074 1082, 1993.

Inoue, T.: On the temperature and effective emissivity determination of semi-transparent cirrus clouds by bispectral measurements in the 10 microns window region, Meteor. Soc. Japan., 63, 88-99, 1985.

Kummerow, C. and Weinman, J. A.: Determining microwave brightness temperatures from precipitating horizontally finite and vertically structured clouds, J. Geophys. Res., 93-D4, 37203728, 1988.

Lau, N. C. and Crane, M. W.: Comparing satellite and surface observations of cloud patterns in synoptic-scale circulation systems, Mon. Wea. Rev., 125, 3172-3189, 1997.

Le Treut, H. and Li, Z.-X.: Sensitivity of an atmospheric general circulation model to prescribed SST changes: Feedback effects associated with the simulation of cloud optical properties, Climate Dynamics, 5, 175-187, 1991.

Lemaître, Y. K, Scialom, G., and Protat, A.: Conditional symmetric instability, frontogenetic forcing and rain-band organization, Quarterly J. Royal Meteor. Soc., 127, 2599-2634, 2001.

Long, C. N. and Ackerman, T. P.: Identification of Clear Skies from Broadband Pyranometer Measurements and Calculation of Downwelling Shortwave Cloud Effects, JGR, 105, No. D12, 15 609-15 626, 2000.

Matthias V., Freudenthaler, V., Amodeo, A., Balin, I., Baslis, D., Bösenberg, J., Chaikovsky, A., Chourdakis, G., Comeron, A., Delaval, A., de Tomasi, F., Eixmann, R., Hagard, A. Konguem, L., Kreipl, S., Matthey, R., Rizi, V., Rodrigues, J. A., Wandinger, U., and Wang, X.: Aerosol lidar intercomparison in the framework of the EARLINET project: 1. Instruments , Appl. Opt., 43, 961-976, 2004.

Menut, L., Flamant, C., and Pelon, J.: Evidence of interaction between synoptic and local scales in the surface layer over the Paris area, Boundary Layer Meteorol., 93, 269-286, 1999.

Michalsky, J. J., Dolce, R., Dutton, E. G., Haeffelin, M., Major, G., Schlemmer, J. A., Slater, D. W., Hickey, J. R., Jeffries, W. Q., Los, A., Mathias, D., McArthur, L. J. B., Philipona, R., Reda, I., and Stoffel, T.: Results from the first ARM diffuse horizontal shortwave irradiance comparison, J. Geophys. Res, Vol. 108, No. D3, 4108, 2003. 
Minnis, P., Garber, D. P., and Young, D. F.: Parameterizations of Reflectance and Effective Emittance for Satellite Remote Sensing of Cloud Properties, J. Atmos. Sci., 55, 3313-3339, 1998.

Morcrette, J. J.: Assessment of the ECMWF model cloudiness and surface radiation fields at the ARM SGP site, Mon. Wea. Rev., 130, 257-277, 2002.

Morcrette, J. J., Smith, L., and Fouquart, Y.: Pressure and temperature dependence of the absorption in longwave radiation parametrizations, Contrib. Atmos. Phys., 59, 455-469, 1986.

Naud, C., Muller, J-P., and Clothiaux, E. E.: Comparison between active sensor and radiosonde cloud boundaries over the ARM Southern great plains site, J. Geophys. Res., 108, D4, 4140, 2003.

Naud, N., Haeffelin, M., Muller, P., Morille, Y., Delaval, A.: Assessment of MISR and MODIS cloud top heights through comparison with a back-scattering lidar at SIRTA, Geophys. Res. Lett., 31, L04114, doi:10.1029/2003GL018976, 2004.

Noel, V., Chepfer, H., Ledanois, G., Delaval, A., and Flamant, P. H.: Classification of effective shape ratios in cirrus clouds based on lidar depolarization ratio, Appl. Opt., 41 (2), 4245-4257, 2002.

Ohmura, A., Dutton, E., Forgan, B., Fröhlich, C., Gilgen, H., Hegner, H., Heimo, A., König-Langlo, G., Müller, G., Philipona, R., Pinker, R., Whitlock, C., Dehne, K., and Wild, M.: Baseline Surface Radiation Network (BSRN/WCRP): New Precision Radiometry for Climate Research, Bulletin of the American Meteorological Society, 79, 2115-2136, 1998.

Orr, B. W. and Kropfli, R. A.: A method for estimating particle fall velocities from vertically-pointing Doppler radar, J. Atmos. Oceanic. Tech., 30, 29-37, 1999.

Philipona, R., Dutton, E. G., Stoffel, T., Michalsky, J., Reda, I., Stifter, A., Wendling, P., Wood, N., Clough, S. A., Mlawer, E. J., Anderson, G., Revercomb, H. E., and Shippert, T. R.: Atmospheric longwave irradiance uncertainty: Pyrgeometers compared to an Absolute Sky-scanning Radiometer, AERI, and radiative transfer model calculations, J. Geophys. Res., 106, 28 129$28142,2001$.

Philipona, R.: Underestimation of solar and diffuse radiation measured at Earth's surface, J. Geophys. Res., 107, 4654, 2002.

Platnick, S., King, M. D., Ackerman, S. A., Menzel, W. P., Baum, B. A., Reidi, J. C., and Frey, R. A.: The MODIS cloud products: Algorithms and examples from Terra. IEEE Trans, Geosci. Remote Sens., 41, 459-473, 2003.

Protat, A., Tinel, C., and Testud, J.: Dynamic properties of clouds and dynamic/microphysical interactions from $94 \mathrm{GHz}$ cloud radar and lidar, Second European Conference on Radar Meteorology, November 2002, Delft, Netherlands, 2002.

Protat, A., Lemaître, Y., and Bouniol, D.: Terminal fall velocity and the FASTEX cyclones, Quarterly Journal Of The Royal Meteorological Society, 129, 1513-1535, 2003.

Protat, A., Pelon, J., Grand, N., Delville, P., Laborie, P., Vinson, J.-P., Bouniol, D., Bruneau, D., Chepfer, H., Delanoë, J., Haeffelin, M., Noël, V., and Tinel, C.: Le projet RALI: Combinaison d'un radar nuage et d'un lidar pour l'étude des nuages faiblement précipitants, La Météorologie, 47, 2004.

Sassen, K.: The polarization lidar technique for cloud research: a review and current assessment, Bull. Amer. Meteor. Soc., 71, 1848-1866, 1991.
Sassen, K. and Cho, B. S.: Subvisual-thin cirrus lidar dataset for satellite verification and climatological research, J. Appl. Meteor., 31, 1274-1285, 1992.

Sassen, K., Comstock, J. M., Wang, Z. and Mace, G.: Cloud and Aerosol Research Capabilities at FARS: the Facility for Atmospheric Remote Sensing, Bull. Amer. Meteor. Soc., 82, 11191138, 2001.

Sadourny, R. and Laval, K.: January and July performance of the LMD general circulation model, in: New Perspectives in Climate Modelling, edited by Berger, A. and Nicolis, C., Developments in Atmospheric Science, 16, Elsevier, 173-198, 1984.

Schneider, J., Balis, D., Böckmann, C., Bösenberg, J., Calpini, B., Chaikovsky, A. P., Comeron, A., Flamant, P., Freudenthaler, V., Hagard, A., Mattis, I., Mitev, V., Papayannis, A., Pappalardo, G., Pelon, J., Perrone, M. R., Resendes, D. P., Spinelli, N., Trickl, T., Vaughan, G., and Visconti, G.: A European Aerosol Research Lidar Network to Establish an Aerosol Climatology (EARLINET), J. Aerosol Sci., 31, S592-S593, 2000.

Smirnov, A., Holben, B. N., Eck, T. F., Dubovik, O., and Slutsker, I.: Cloud screening and quality control algorithms for the AERONET data base, Rem. Sens. Env., 73(3), 337-349, 2000.

Stokes, G. M., and Schwartz, S. E.: The Atmospheric Radiation Measurement Program: Programmatic Background and Design of the Cloud and Radiation Testbed, Bull. Amer. Meteor. Soc., 75, 1201-122, 1994.

Stull, R. B.: An Introduction to Boundary Layer Meteorology, Kluwer Academic Publishers, Dordrecht, 666 pp, 1988.

Tabary, P. and Scialom, G.: MANDOP analysis over complex orography in the context of the MAP experiment, J. Atmos. Oceanic Technol., 18, 1293-1314, 2001.

Testud, J., Oury, S., Black, R. A., Amayenc, P., and Dou, X.-K.: The Concept of "Normalized" Distribution to Describe Raindrop Spectra: A Tool for CloudPhysics and Cloud Remote Sensing, J. Appl. Meteor., 40 (6), 1118-1140, 2001.

Tinel, C., Testud, J., Pelon, J., Hogan, R. H., Protat, A., Delanoë, J., and Bouniol, D.: The retrieval of ice cloud properties from cloud radar and lidar synergy, J. Appl. Meteor., in press, 2005.

Troen, I. and Mahrt, L.: A simple model of the atmospheric boundary-layer; Sensitivity to surface evaporation, Bound. Layer Meteor., 37, 129-148, 1986.

Tselioudis, G. and Jakob, C.: Evaluation of midlatitude cloud properties in a weather and a climate model: dependence on dynamic regime and spatial resolution, J. Geophys. Res., 107, D24, 4781, doi: 10.1029/2002JD002259, 2002.

Vautard, R., Beekmann, M., Roux, J., and Gombert, D.: Validation of a hybrid forecasting system for the ozone concentrations over the Paris area, Atmos. Environ., 35, 2449-2461, 2001.

Ulden, A. P. van and Wierenga, J.: Atmospheric Boundary Layer Research at Cabauw, Boundary-Layer Meteorology, Vol. 78, 39 69, 1996.

Williams, K. D., Ringer, M. A., and Senior, C. A.: Evaluating the cloud response to climate change and current climate variability, Climate Dynamics, 20, 705-721, 2003. 